\title{
Cyclic performance of a monopile in spatially variable clay using an advanced constitutive model
}

\author{
T. S Charlton ${ }^{1}$, M. Rouainia ${ }^{1}$ \\ ${ }^{1}$ School of Engineering, Newcastle University, Newcastle upon Tyne, NE1 7RU, UK
}

\begin{abstract}
The performance of monopiles in cohesive soils is of great interest for future offshore wind farm developments, particularly under the cyclic loads experienced in the ocean environment. Clay behaviour during undrained cyclic loading is complex and involves the accumulation of plastic strains, generation of excess pore-water pressures and degradation of initial stiffness. In this paper, the cyclic performance of a laterally-loaded monopile in spatially variable clay is investigated for the first time. A kinematic hardening constitutive model is used in a 3D finite element analysis to capture the hysteretic stress-strain behaviour of the clay. The monopile is installed in overconsolidated London Clay, which is present at several offshore wind farms in the Thames Estuary. The finite element model is coupled with random field representations of initial stiffness and clay structure. The statistical characterisation of the random fields was undertaken considering parameter ranges observed in laboratory tests. Under one-way cyclic loading, the monopile showed ratcheting behaviour, where pile rotation accumulates with increasing numbers of load cycles. The cyclic secant stiffness also increased due to the generation of negative excess pore-pressures in the clay. This behaviour occurred in both homogeneous and spatially variable clay. The monopile was also subjected to an extreme dynamic event and the soil response around the monopile showed increasing variability in stress-strain response and generation of excess pore-water pressure over time as plastic strain accumulated. However, the overall behaviour of the foundation was governed by a spatial average of the mobilised clay. The range in monopile response demonstrates how the natural spatial variability of clay can have a strong influence on monopile performance.
\end{abstract}

Keywords: Monopile, Offshore Wind, Finite Element, Constitutive Modelling, Uncertainty Quantification 
2

\section{Introduction}

Monopiles have proven to be an effective foundation for offshore wind turbines (OWTs) in waters of up to $35 \mathrm{~m}$ depth and currently account for $81 \%$ of existing OWT foundations in Europe, including 70\% of those installed in 2019 [53]. Figure 1 shows the main components of a monopile-supported OWT. Monopiles are stiff piles driven into the seabed and are typified by large diameters $(>3 \mathrm{~m})$ and a length to diameter ratio of around 5 . The offshore environment subjects monopiles to high numbers of load cycles during their lifetime and this cyclic loading can lead to permanent displacement and rotation of the pile. To maintain safe operation of the OWT, the monopile must be designed so that the rotation does not exceed a serviceability limit, for example $0.5^{\circ}[15]$. In addition, long-term cyclic loading may affect the stiffness of the foundation response and cause problematic resonance effects by shifting the natural frequency of the OWT. The latter effect is also influenced by the amount of damping provided by the foundation system [10], which is dependent upon the hysteretic response of the soil.

Prediction of monopile performance under lateral cyclic loading is a difficult task and most research has focused on monopiles in sand. Several laboratory studies have used empirical relationships to describe the development of rotation and stiffness, which generally evolve with the number of cycles according to a logarithmic function or power law [e.g. 37, 38, 41, 12, 31, 1]. Although useful for initial design, such relationships do not describe the foundation behaviour in each cycle and how the hysteretic response and damping may change under loading. Cycleby-cycle assessment of monopile behaviour requires more advanced analysis, with constitutive models capable of capturing the governing mechanisms. Houlsby et al. [29] introduced a hyperplasticity model for the general ratcheting response of a structure under cyclic loads, describing the continuous accumulation of permanent deformations with number of cycles, and this was calibrated by Abadie et al. [2] for monopiles in dry sand. In saturated sands, coupled hydro-mechanical finite element (FE) analyses incorporating multi-surface plasticity models have shown that monopiles under cyclic loading can generate a partially drained response in the soil, with monopile performance influenced by transient pore pressure generation and dilative and contractive (liquefying) responses [4, 11].

Monopile performance in cohesive soils is similarly complex and will become increasingly significant as offshore wind energy continues to expand into new regions around the world, including China, Japan, Taiwan, and the USA [25]. Several centrifuge testing programmes have been carried out in an attempt to better understand the cyclic behaviour of monopiles in clay [e.g 55, 34, 33]. These studies have shown that monopile response in clay is controlled by 
the interaction of several physical phenomena including remoulding, the generation of excess pore water pressures and periods of reconsolidation over the long-term. However, there is still much uncertainty as to how monopiles will behave in heterogeneous natural clays in the field.

Le et al. (2014) reported a case study of the Sheringham Shoal wind farm, characterized by two heavily overconsolidated clay strata (Bolders Bank and Swarte Bank formations) interbedded with a layer of dense sand. Both the undrained shear strength $\left(s_{u}\right)$ and small-strain stiffness of the clay layers showed considerable variability, and the degradation of initial stiffness under monotonic and cyclic loading was an important factor in design. Research into the effect of spatial variability on monopiles in clay has so far focused on the undrained static lateral capacity in coupled random field-FE analyses, generally using linear elastic-perfectly plastic constitutive models $[26,16]$. The effect of spatial variability on the cyclic performance of monopiles has received little attention. Depina et al. [13] used a stiffness degradation model, where stiffness reduces with cycle number according to an empirical law, combined with a random field of stiffness to investigate the influence of spatial variability on the cyclic performance of a monopile in dense sand through FE analysis. It was found that spatial variability could affect the accumulated displacement and rotation of the pile considerably. To date, no studies of monopile response under cyclic loading in spatially variable clay, capturing the governing mechanisms of the clay response through a suitably advanced constitutive model, have yet been made.

In this paper, the cyclic behaviour of a laterally-loaded monopile in spatially variable London Clay will be investigated using 3D FE analysis. A kinematic hardening constitutive model is used to capture the nonlinear, hysteretic stress-strain behaviour of the clay under cyclic loading. The model is also capable of simulating the degradation of small-strain stiffness under increasing strain that is an important feature of clay behaviour around monopiles. Spatial variability is represented by random fields and the effect on monopile performance under cyclic loading is quantified by Monte Carlo simulation. The stress-strain behaviour of the clay and generation of excess pore water pressures are analysed to provide an insight into the mechanisms governing the monopile response. Both one-way cyclic loading, with different maximum intensities, and dynamic loading are considered to assess a range of realistic loading regimes.

\section{Constitutive model for London Clay}

\subsection{Kinematic hardening model}

London Clay is a stiff, overconsolidated clay with behaviour characterised by a natural structure. The term structure is used to describe the microscale particle arrangement (soil fabric) 


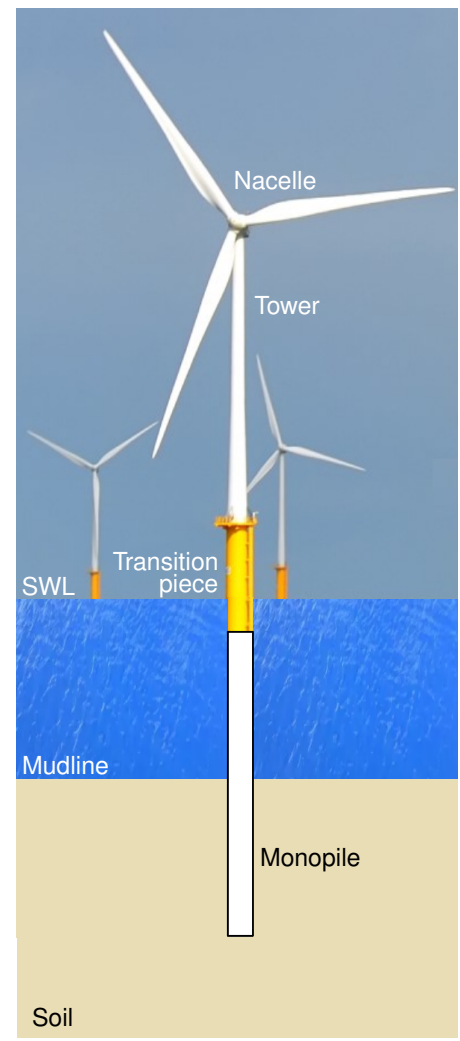

Figure 1: Monopile foundation for an offshore wind turbine. SWL = Still Water Level.

and non-frictional bonding between particles that lead to an increased intact shear strength and brittle response [22]. In the context of monopile foundations, London Clay holds interest as it is present in the Thames Estuary where the London Array and Kentish Flats wind farms are located.

In this study, the clay is simulated using the RMW (Rouainia-Muir Wood) model [47], a multi-surface effective stress model based on the critical state framework. The formulation is apt for modelling both the natural structure of London Clay and the hysteretic stress-strain behaviour under dynamic or cyclic loads. The RMW model extends the classic Modified Cam Clay (MCC) [48] model by including an outer surface to account for the effect of structure on the mechanical response of a soil. The structure surface collapses towards the MCC reference surface, which describes the behaviour of fully remoulded material, while the elastic domain is enclosed in a kinematic hardening bubble that moves inside the structure surface. The initial structure is defined by the parameter $r_{0}$, which represents the ratio of structure surface size to reference surface size $\left(r_{0} \geq 1\right)$. Structure degradation is modelled by a damage law, which is written in incremental form as: 


$$
\dot{r}=\frac{-k(r-1)}{\lambda^{*}-\kappa^{*}} \dot{\varepsilon}_{d}
$$

where $r$ is the current structure in the soil. The damage law is a monotonically decreasing function of a damage strain, $\dot{\varepsilon}_{d}$. The parameter $k$ controls the rate of structure degradation, while $\lambda^{*}$ and $\kappa^{*}$ are respectively the slope of the normal compression line and swelling line in a logarithmic specific volume-logarithmic mean stress plot. Damage strain is calculated from the volumetric $\left(\varepsilon_{v}^{p}\right)$ and shear $\left(\varepsilon_{q}^{p}\right)$ components of plastic strain as follows:

$$
\dot{\varepsilon}_{d}=\left[(1-A)\left(\varepsilon_{v}^{p}\right)^{2}+A\left(\varepsilon_{q}^{p}\right)^{2}\right]^{1 / 2}
$$

where $A$ is a dimensionless parameter that determines the relative contributions of $\varepsilon_{v}^{p}$ and $\varepsilon_{q}^{p}$ to the damage strain.

Degradation of stiffness is captured through a bounding surface relationship, with stiffness dependent on the distance between the kinematic hardening bubble and structure surface. The combination of bounding surface plasticity and kinematic hardening is well-suited to capturing both the hysteretic response of clays during a load cycle and the degradation of stiffness under repeated cycles. This was demonstrated by Elia and Rouainia [19] through an extensive validation of the RMW model against a range of undrained cyclic laboratory tests on natural and remoulded clays.

The initial stiffness, $G_{0}$, is described using a nonlinear elastic formulation by Viggiani and Atkinson [51]:

$$
\frac{G_{0}}{p_{r}^{\prime}}=A_{g}\left(\frac{p^{\prime}}{p_{r}^{\prime}}\right)^{n_{g}} R_{0}^{m_{g}}
$$

where $p^{\prime}$ is the mean effective pressure with a reference value $p_{r}^{\prime}$ of $1 \mathrm{kPa}, R_{0}$ is the isotropic overconsolidation ratio $\left(R_{0}=2 P_{c} / p^{\prime}\right.$ with $P_{c}$ the centre of the reference surface) and $A g, n_{g}$ and $m_{g}$ are dimensionless stiffness parameters that can be related to the plasticity index [51].

For analysis of boundary value problems, the RMW model has been implemented into finite element procedures by an explicit stress integration scheme [56]. The model has been successfully used to analyse a range of static geotechnical problems [e.g. 43, 7]. Charlton and Rouainia [8] recently implemented the model into a probabilistic framework to analyse the effect of the spatial variability of clay structure on the uplift capacity of a buried subsea pipeline. Dynamic 
Table 1: Calibrated RMW parameters for London Clay. Shading indicates random parameters in the current study.

\begin{tabular}{ll}
\hline Slope of normal compression line, $\lambda^{*}$ & 0.0965 \\
Slope of swelling line, $\kappa^{*}$ & 0.0459 \\
Critical state stress ratio, $M$ & 0.85 \\
Ratio of size of bubble and reference surface, $R$ & 0.016 \\
Stiffness interpolation parameter, $B$ & 4.0 \\
Stiffness interpolation exponent, $\psi$ & 6.0 \\
Initial degree of structure, $r_{0}$ & $2.5\left(\mu_{r_{0}}\right)$ \\
Destructuration strain parameter, $A$ & 0.75 \\
Destructuration parameter, $k$ & 1.0 \\
Non-dimensional stiffness parameter, $A_{g}$ & $430\left(\mu_{A_{g}}\right)$ \\
Non-dimensional stiffness parameter, $n_{g}$ & 0.87 \\
Non-dimensional stiffness parameter, $m_{g}$ & 0.28 \\
\hline
\end{tabular}

applications have involved simulating the response of shallow foundations, embankments and tunnels to seismic loads $[17,18,5]$.

\subsection{Calibrated parameters}

The RMW parameters were calibrated for London Clay by Gonzàlez et al. [23]. The calibration was based on extensive laboratory characterisation presented by Gasparre [20] and Hight et al. [27]. The lithological unit B2(a) has been considered in this study and the model parameters are given in Table 1. The experimental measurements of small-strain stiffness collated by Gonzàlez et al.[23] showed such variability that two cases of $A_{g}$ (low and high) were considered, equal to 245 and 615 for low and high stiffness respectively. The overconsolidation ratio was calibrated as 4.5 . The clay has a bulk unit weight of $19 \mathrm{kN} / \mathrm{m}^{3}$ and a critical state friction angle of $22^{\circ} ; K_{0}$ was taken as 1.0. In this paper, both the initial degree of structure $\left(r_{0}\right)$ and the small-strain stiffness $\left(A_{g}\right)$ are modelled as random fields to investigate the effect of variability in strength and stiffness on the performance of a monopile under lateral cyclic loading.

\section{The variability of London Clay}

\subsection{Clay structure}

Considerable natural variability in undrained shear strength is a commonly observed feature of London Clay [28]. Stress-strain behaviour in undrained triaxial tests on samples from a range of lithological units have shown similar characteristics, namely strain-softening and dilatant behaviour [22]. Differences in peak strength are a result of variation in cementing, density and plasticity index in addition to fissures and discontinuities [23]. Using the RMW, this variability 
can be captured through the degree of structure. Fig. 2 shows numerical and laboratory results of undrained triaxial compression tests on London Clay. A higher $r_{0}$ results in a higher peak strength while the strain-softening behaviour remains. Each numerical prediction tends to the same remoulded strength at large strains as the parameters controlling the reference surface are unchanged. The calibrated value of $r_{0}$ fits the experimental data satisfactorily but the figure shows how the clay response can vary.
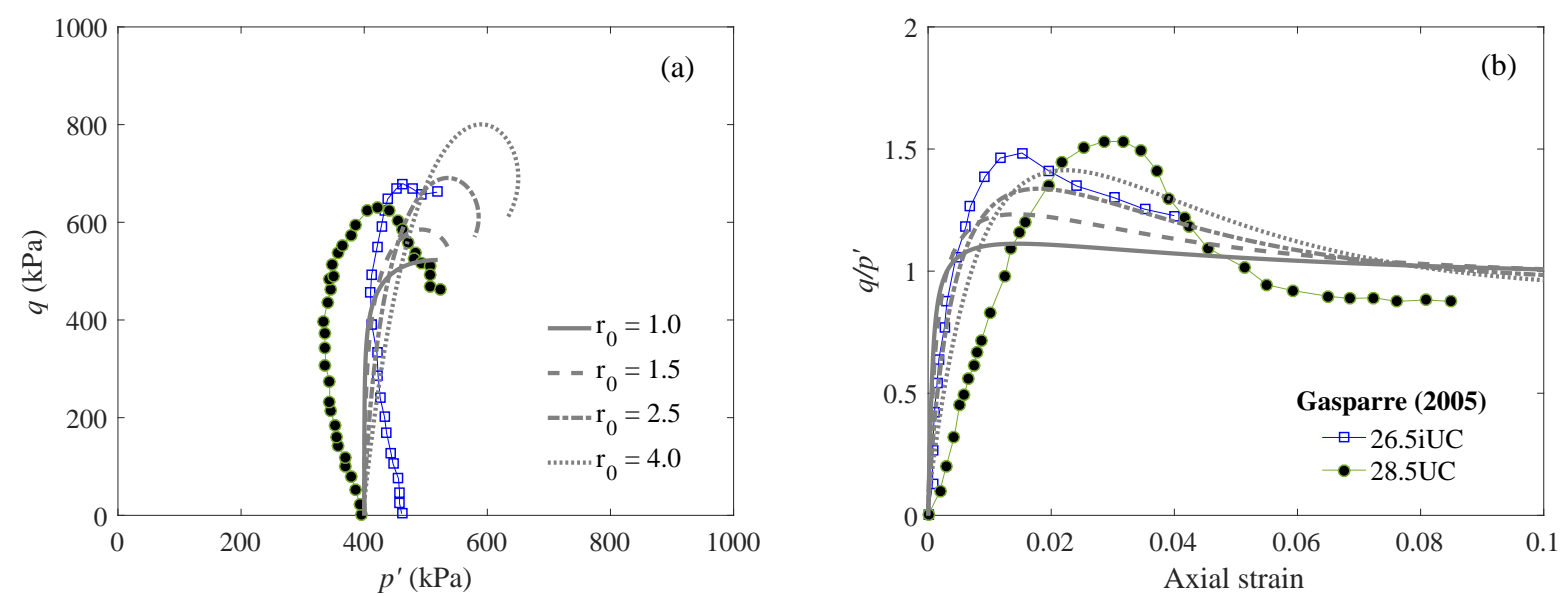

Figure 2: RMW model predictions and laboratory data for undrained triaxial compression tests on London Clay: (a) stress path; (b) stress-strain response. Laboratory data from Gasparre [20]; $26.5=26.5 \mathrm{~m}$ sample depth, $\mathrm{i}=$ isotropic consolidation, $\mathrm{UC}=$ undrained compression test.

The statistics of $r_{0}$ were based on those of $s_{u}$, which is generally assumed to follow a lognormal PDF [32]. A shifted lognormal distribution was assumed for $r_{0}$, with a lower bound equal to 1 . The COV of $r_{0}$ was chosen to be 0.3 , based on the typical range of variability of $s_{u}$ reported in the literature [44], with the mean being equal to the calibrated value $\left(\mu_{r_{0}}=2.5\right)$. The COV is a slightly lower value than found by Le et al. [35] at Sheringham Shoal for several clay layers $\left(\mathrm{COV}_{s_{u}}=0.49-0.6\right)$, but only a limited number of tests were available at that site. A square exponential autocorrelation function was assumed, again based on field data of $s_{u}$ [30], and the autocorrelation distances in horizontal and vertical directions were taken to be $10 \mathrm{~m}$ and $1 \mathrm{~m}$ respectively, which is characteristic of many soil parameters [44].

The suitability of these assumptions is illustrated in Fig. 3, which shows a profile of $r_{0}$ with depth at Heathrow T5. The laboratory estimates of $r_{0}$ are based on oedometric results [21], and show the maximum and minimum values at a range of depths. The random field realisation captures the natural fluctuation of clay structure in the soil mass. It should be noted that clay structure was not observed to follow an increasing trend with depth [23], and so $\mu_{r_{0}}$ is constant. 


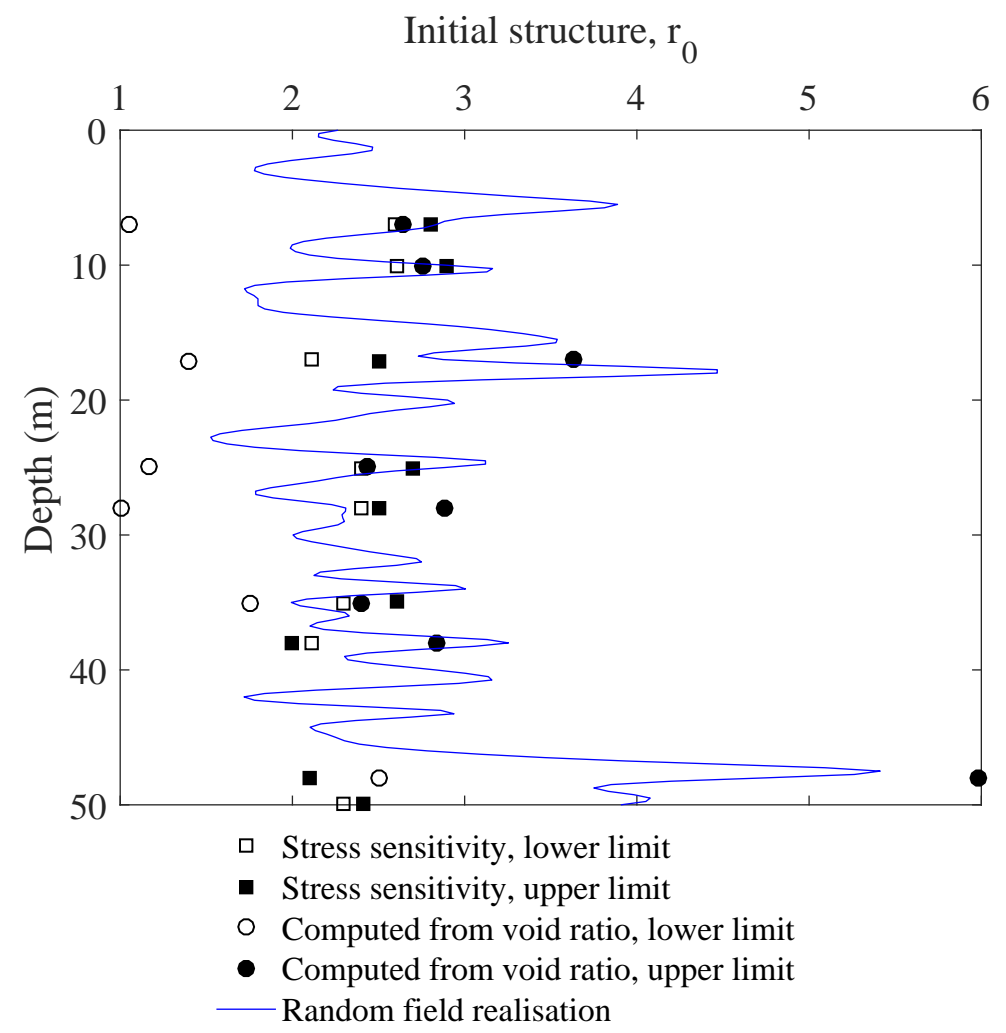

Figure 3: Profile of $r_{0}$ with depth showing laboratory data from Heathrow T5 site (replotted from [23]); data from references therein) and random field realisation.

\subsection{Small-strain stiffness}

Small-strain stiffness is particularly important for OWT foundations. The initial shear modulus, $G_{0}$, of the soil influences the natural frequency of the structure and its performance at the fatigue and serviceability limit states. The degradation of $G_{0}$ due to environmental loading also must be known to avoid resonance with the excitation frequencies and keep accumulated rotation within the specified limit. Le et al. [35] found that the overconsolidated clays at the Sheringham Shoal offshore wind farm showed high to very high small-strain stiffness and significant stiffness degradation under both monotonic and cyclic loads, and this was identified as a particularly important design issue. Both the small-strain stiffness and degradation behaviour showed a high variability (e.g. $\left.\mathrm{COV}_{G_{0}}=0.37-0.67\right)$.

The small-strain stiffness behaviour of London Clay has been characterised in studies by Hight et al. [28], Gasparre [20], and Hight et al. [27]. The data is summarised in Fig. 4 in terms of the undrained secant elastic modulus $E_{u, s e c}$ normalised by the initial mean effective stress $p_{0}^{\prime}$. The experimental bounds show that at very small strains $\left(10^{-5}\right.$ to $\left.10^{-4}\right)$, a large range of stiffness values were recorded, indicating the uncertainty associated with the initial stiffness. 
The width of the bounds becomes much narrower at larger strains. The variability of smallstrain stiffness and its degradation with strain is represented by modelling the RMW parameter $A_{g}$ as a random field. A lognormal distribution is chosen to ensure $A_{g}$ takes positive values. Based on an average of the high and low stiffness cases considered by Gonzàlez et al. [23], $\mu_{A_{g}}$ $=430$. The $\mathrm{COV}$ of $A_{g}$ and $G_{0}$ are equivalent by way of Eq. $3 ; \mathrm{COV}_{A_{g}}$ is therefore taken as 0.4, which fits into the range identified at Sheringham Shoal.

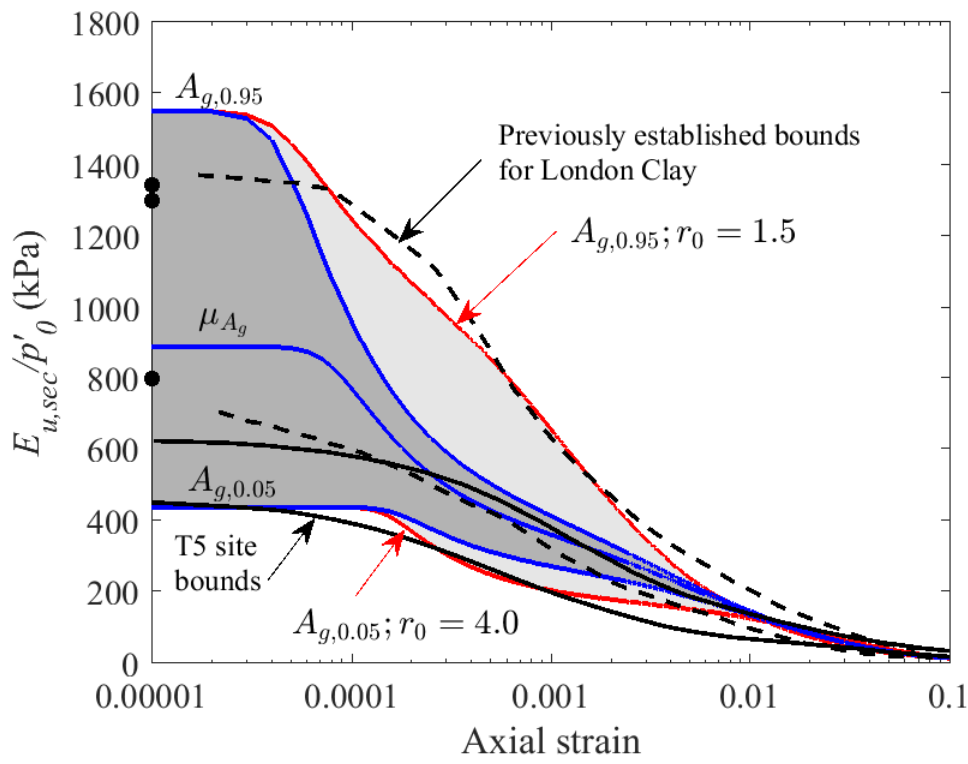

- Data from Grammitikopoulou et al. (2008) and Yimsiri (2001)

Dark shading indicates area between 0.05 and 0.95 quantiles of $A_{g} \sim \ln N(2.5,1)$ with $r_{0}=\mu_{r_{0}}=2.5$

Figure 4: Stiffness degradation of London Clay in undrained triaxial compression tests. Numerical simulations undertaken with $r_{0}=2.5$ unless otherwise stated.

Fig. 4 also shows how the variability in stiffness degradation is captured. The solid blue lines show the stiffness degradation curves for the mean value of $A_{g}\left(\mu_{A_{g}}\right)$ and the 5\% and 95\% quantiles, denoted $A_{g, 0.05}$ and $A_{g, 0.95}$ respectively, when $r_{0}=\mu_{r_{0}}=2.5$. The dark shaded area between the $A_{g, 0.05}$ and $A_{g, 0.95}$ curves on Figure 4 therefore covers $90 \%$ of the stiffness degradation behaviour, conditional on $r_{0}=2.5$. Experimental studies have observed that structure and small-strain stiffness are related, with natural clay having a higher initial stiffness and showing a more rapid stiffness degradation with strain than remoulded soil [e.g. 6]. This behaviour is illustrated in Fig. 4, where degradation curves corresponding to $\left\{A_{g, 0.95}, r_{0}=1.5\right\}$ and $\left\{A_{g, 0.05}, r_{0}=4.0\right\}$ are shown. When $r_{0}$ is lower, stiffness degradation does not occur as quickly, while a faster decay is observed for a higher $r_{0}$. The two examples represent extreme 
cases, but also show that the experimental bounds can be sufficiently covered at small strains. Experimental data suggests a strong positive correlation between clay structure and small-strain stiffness $[6,50]$. To model this dependency, the random field of $A_{g}$ was assumed to have the same autocorrelation structure as $r_{0}$ and the two fields are assigned a cross-correlation of $\rho_{r_{0} A_{g}}$ $=0.8$.

\section{Computational framework}

\subsection{Finite element model}

A 3D FE model was constructed in PLAXIS 3D AE [45] to investigate the effect of lateral cyclic loading on a monopile in spatially variable London Clay. Further information on the modelling of monopiles in PLAXIS 3D may be found in [46]. The monopile was based on centrifuge tests carried out by Lau [34], where a pile with a diameter of $3.8 \mathrm{~m}$ and an embedded length of $20 \mathrm{~m}$ (in prototype scale) was considered. The model pile was constructed from aluminium $\left(E=70 \mathrm{GPa}, \rho=2700 \mathrm{~kg} / \mathrm{m}^{3}\right)$ to ensure that the bending stiffness and mass were representative of a steel pile with a typical $\sim 56 \mathrm{~mm}$ wall thickness.

The FE mesh is shown in Fig. 5, consisting of 14955 10-node tetrahedral elements. The monopile is modelled by a block of linear elastic material, with bending stiffness and unit weight equivalent to the aluminium pile. Only half of the pile is modelled in order to minimise computational time and installation effects are ignored, with the monopile being wished-inplace at the start of each simulation. Standard fixities are applied: the base of the model is fully fixed while the lateral boundaries are fixed in the normal direction. All boundaries are sufficiently distant such that boundary effects on the monopile behaviour are avoided. A lateral load was applied at the still water level, $30 \mathrm{~m}$ above the mudline.

Soil-structure interaction is modelled through interface elements between the elastic block of the pile and the clay. The pile-soil interface strength is reduced by considering an effective friction angle, $\phi^{\prime}$, of $14^{\circ}$, which is two-thirds that of the intact clay. Undrained conditions apply for all simulations.

The characteristics of the cyclic loading can be described by two parameters, $\zeta_{b}$ and $\zeta_{c}$, introduced by LeBlanc [36] to describe respectively the magnitude of the cyclic load and the extent of load reversal. Since the analyses are load-controlled, the parameters are defined in terms of the applied force as follows: 


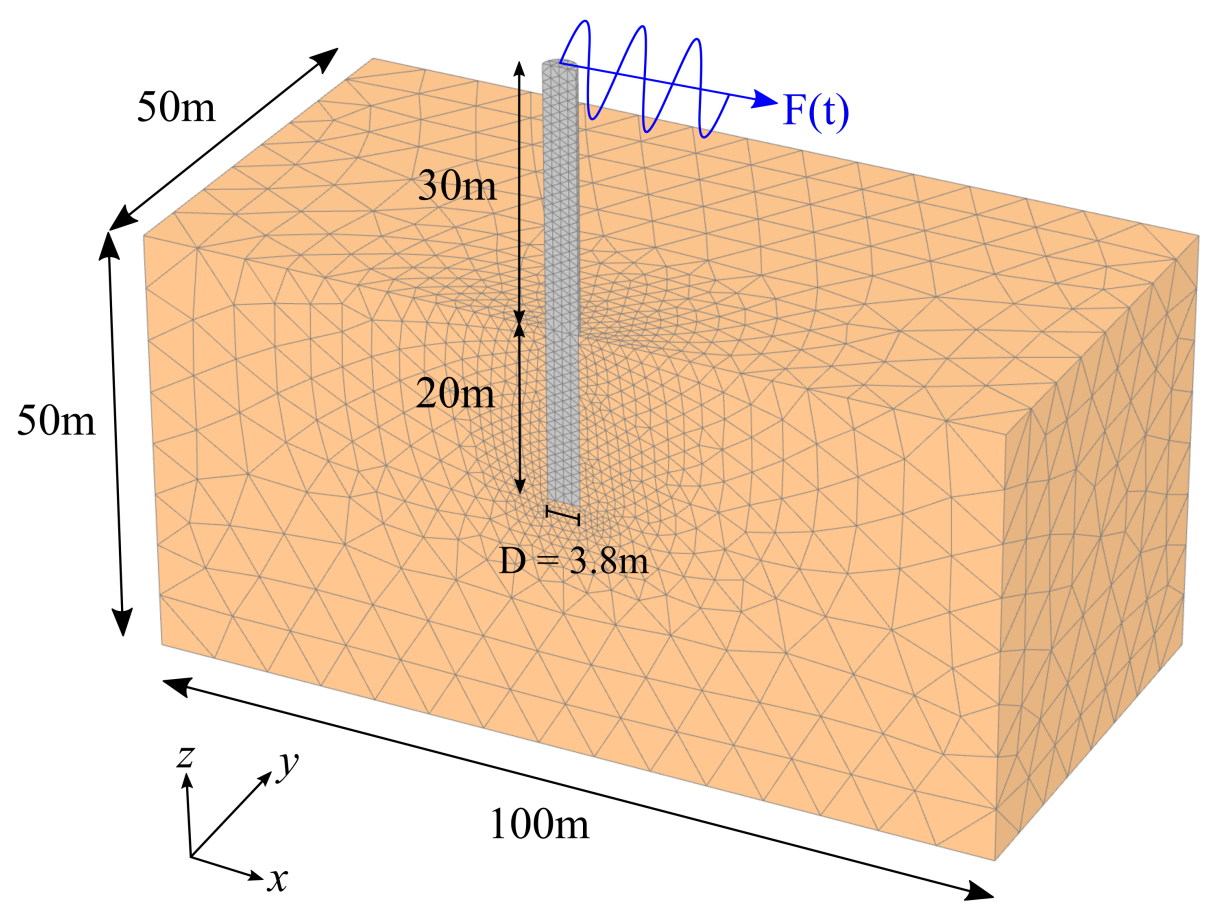

Figure 5: Finite element mesh.

$$
\begin{gathered}
\zeta_{b}=\frac{F_{\max }}{F_{R}} \\
\zeta_{c}=\frac{F_{\min }}{F_{\max }}
\end{gathered}
$$

where $F_{R}$ is the static capacity and $F_{\min }$ and $F_{\max }$ are the maximum and minimum load applied in each cycle, respectively. In this paper, one-way load cycles are considered $\left(\zeta_{c}=0\right)$ in addition to a dynamic load of irregular two-way load cycles. Three one-way load cycles of different magnitude were applied to assess performance at both the fatigue $\left(\zeta_{b}=0.18,0.25\right)$ and serviceability limit states $\left(\zeta_{b}=0.47\right)[38]$. The one-way cyclic loads were applied through a dynamic sinusoidal force with a frequency of $0.2 \mathrm{~Hz}$, imposed at the top of the pile. Viscous lateral boundaries were used to absorb outgoing energy in dynamic analyses. The static capacity in the deterministic case, where both $r_{0}$ and $A_{g}$ are equal to their mean values and homogeneous across the soil domain, was determined to be $4.66 \mathrm{MN}$ during a pushover test.

\subsection{Monte Carlo simulation}

Monte Carlo simulation was used to assess the effect of the spatial variability of clay structure and small-strain stiffness on the response of the monopile. The computational framework is 
summarised in Figure 6. The random fields were generated on a 3D stochastic mesh before being linearly interpolated to the integration points of the FE model for computation of the monopile response under cyclic loading. From a set of $N$ simulations, the response variability can be quantified.

The lognormal distribution is parametrised by $\alpha$ and $\beta$, respectively the mean and standard deviation of the logarithm of the random variable. The shifted lognormal distribution has an additional parameter, $\delta$, to specify the lower bound. The random fields of $r_{0}$ and $A_{g}$ were therefore generated as follows:

$$
\begin{gathered}
r_{0}(x, y, z)=\delta_{r_{0}}+\exp \left[\alpha_{r_{0}}+\beta_{r_{0}} G_{r_{0}}(x, y, z)\right] \\
A_{g}(x, y, z)=\exp \left[\alpha_{A_{g}}+\beta_{A_{g}} G_{A_{g}}(x, y, z)\right]
\end{gathered}
$$

where $G_{r_{0}}$ and $G_{A_{g}}$ are correlated standard Gaussian random fields of zero mean and unit variance. A series expansion method [39] was used to simulate the random fields, which were cross-correlated following Vořechovský [52].

The spacing of the grid points in the stochastic mesh was less than $L_{c} / 2$ in $x-, y-$, and $z$-directions, where $L_{c}$ is the corresponding autocorrelation distance; this has been shown to be a suitable criterion for the square exponential function by Sudret and Der Kiureghian [49]. The stochastic mesh was also extended $1 \mathrm{~m}$ beyond the FE mesh.

\section{Results and discussion}

\subsection{One-way cyclic loading}

Due to the computational demands of a highly-nonlinear constitutive model coupled with complex loading and soil-structure interaction, the number of applied one-way load cycles was limited to 50. Response statistics were obtained from 100 Monte Carlo simulations. Example random field realisations are shown in Figure 7.

The lateral displacement along the monopile after 50 load cycles is shown in Figure 8. The displacement that occurs in the deterministic analysis is shown for reference. The displacement mechanism is similar in both spatially variable and homogeneous clay; the monopile behaves rigidly and rotates around a point at depth $\sim 75 \%$ of the embedded length. The Monte Carlo 


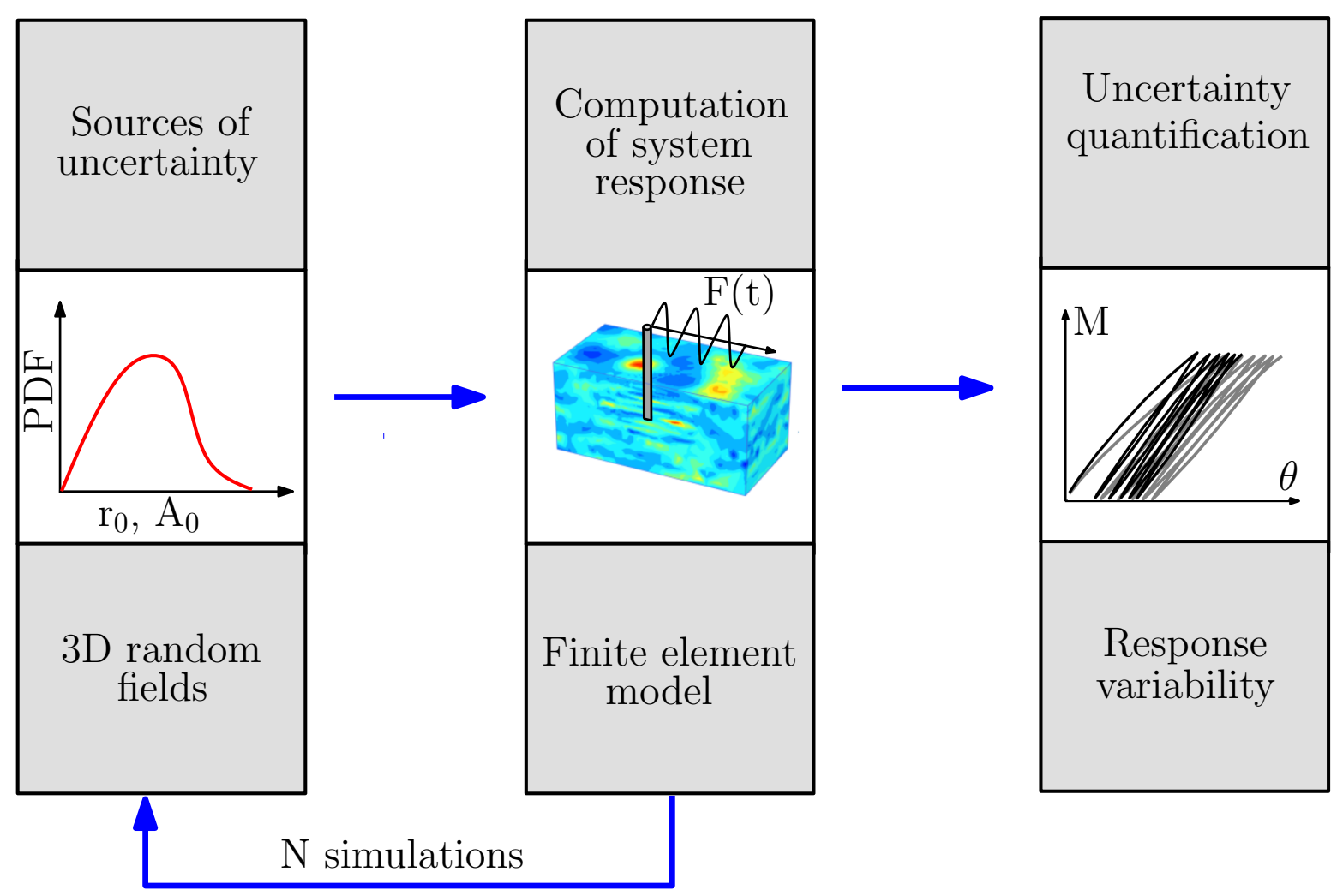

Figure 6: Computational framework for Monte Carlo simulation.
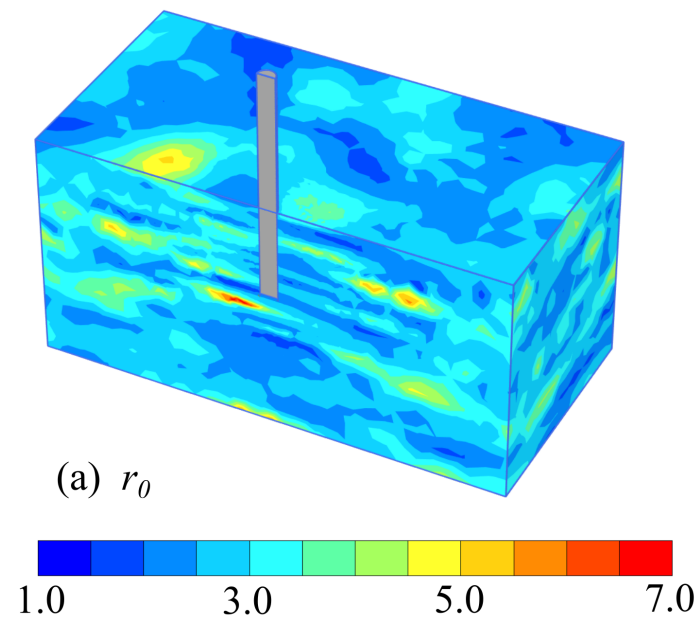

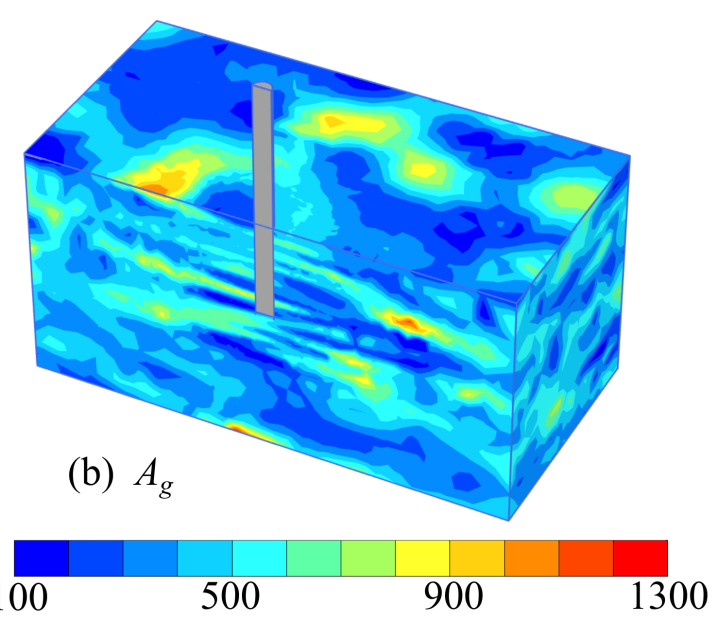

Figure 7: Random field realisations of (a) $r_{0}$ and (b) $A_{g}$. 
simulations show that the greatest range in pile displacement occurs at the mudline, while the centre of rotation remains essentially unchanged in all cases.
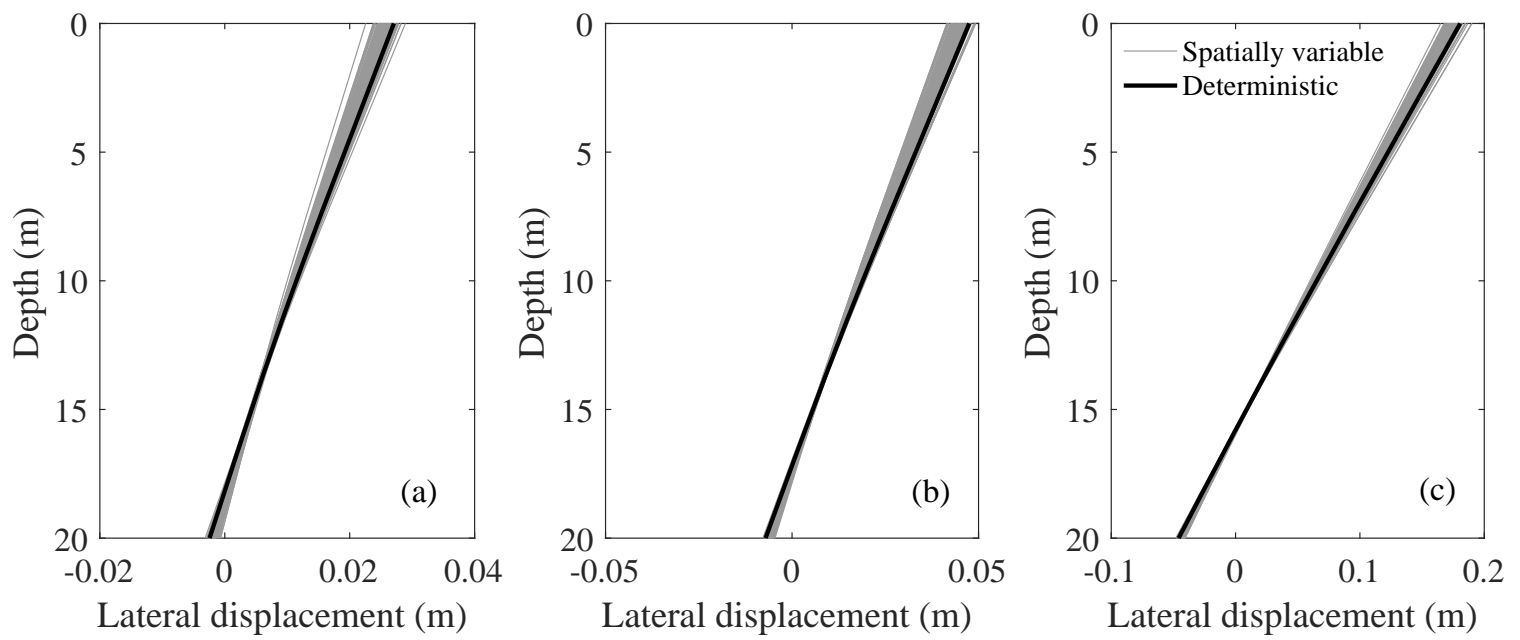

Figure 8: Lateral displacement of the monopile after 50 load cycles, with 100 simulations in spatially variable clay and the deterministic case. (a) $\zeta_{b}=0.18$, (b) $\zeta_{b}=0.25$, and (c) $\zeta_{b}=0.47$.

Fig. 9 shows the bending moment-rotation behaviour at the mudline. In the deterministic analysis, the pile rotation does not return to zero as the load is released. Instead, nonlinear hysteresis loops form with energy dissipated during the load cycle. With continuing cycles of loading-unloading the pile experiences increasing rotation, or ratcheting. The rate of rotation accumulation consistently decreases in each cycle in an attenuation mechanism. Shakedown, where the monopile ultimately reaches an elastic state with constant displacement, does not occur in the number of cycles observed in this study. Ratcheting occurs at each loading intensity, with rotation accumulating at a faster rate as the size of the cyclic load increases.

In spatially variable clay, the general behaviour follows that observed in the deterministic analysis, with hysteresis loops forming that tighten with increasing numbers of load cycles. However, the rotation that occurs in each cycle can vary due to the changing spatial distribution of small-strain stiffness and clay structure around the monopile.

The accumulated rotation can be normalised as $\Delta \theta_{N} / \theta_{1}$, where $\Delta \theta_{N}=\theta_{N}-\theta_{1}$. The maximum rotation in the first cycle $\left(\theta_{1}\right)$ is equivalent to the static rotation and $\theta_{N}$ is the maximum rotation in cycle $N$. The normalised accumulated rotation is plotted in Figure 10, with the normalising factor $\theta_{1}$ updated for each simulation. After an initially rapid increase, the accumulated rotation increases linearly on a $\log -\log$ scale. The spatial variability of the clay does not affect the trend of attenuation of the accumulated rotation with the number of load cycles.

The variability in normalised rotation as a function of the number of cycles is shown in Fig. 

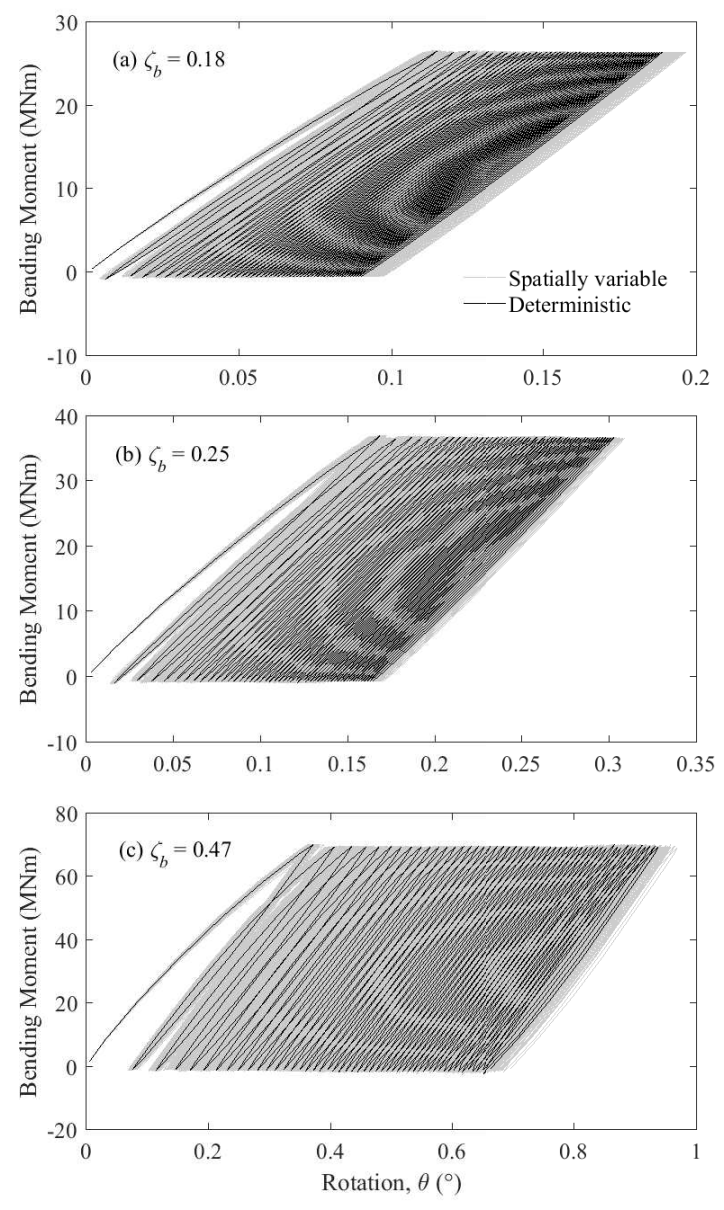

Figure 9: Bending moment - rotation of the monopile at the mudline in spatially variable clay (100 simulations) after 50 load cycles with (a) $\zeta_{b}=0.18$, (b) $\zeta_{b}=0.25$, and (c) $\zeta_{b}=0.47$. 

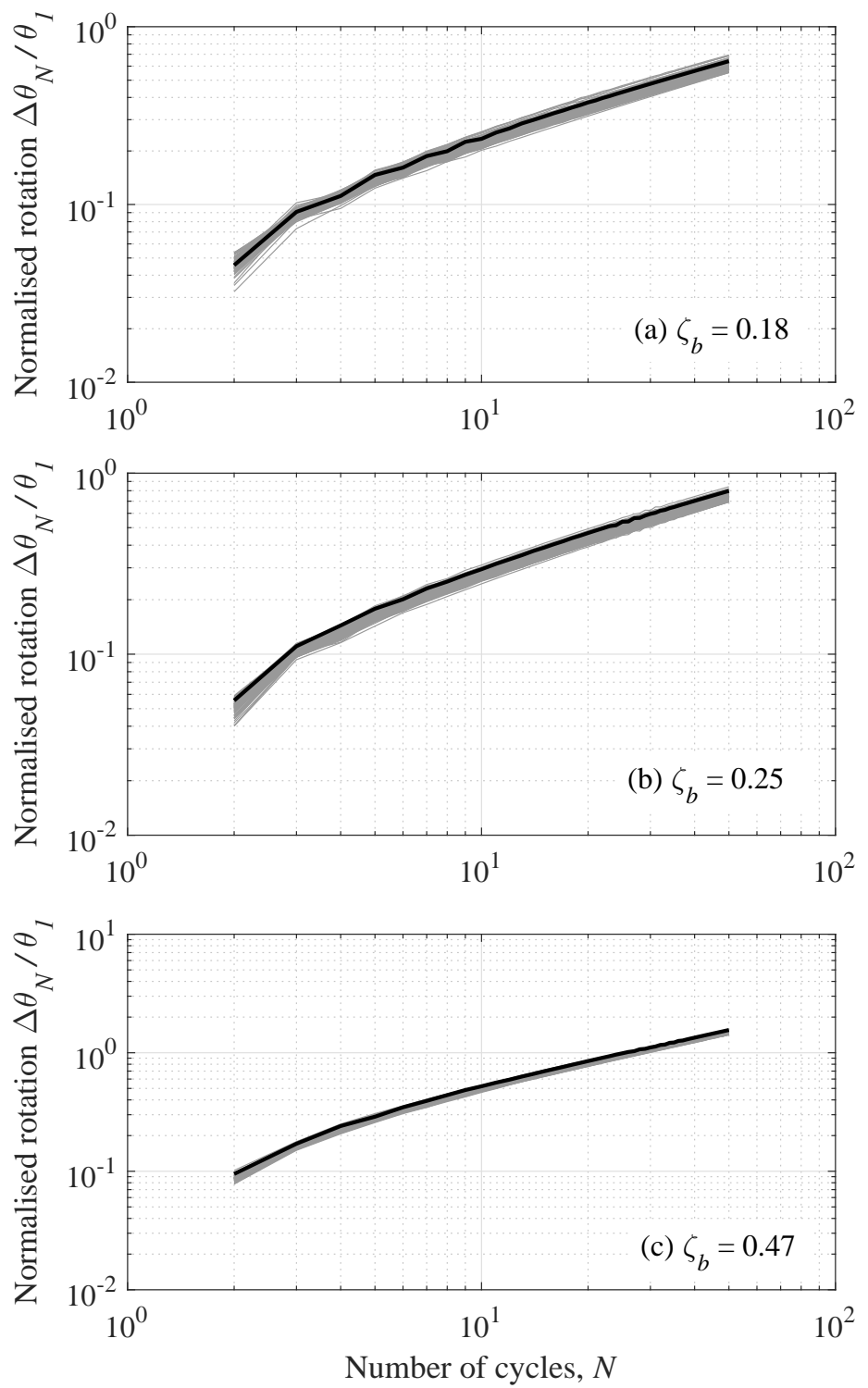

Figure 10: Normalised accumulated rotation at the mudline in spatially variable clay. 
11, where $95 \%$ confidence intervals are computed by bootstrap resampling. After an initial reduction, the $\mathrm{COV}$ remains fairly constant with increasing cycles at $\zeta_{b}=0.18$ and 0.25 , while steadily reducing at $\zeta_{b}=0.47$. There is also a reduction in $\mathrm{COV}$ at $\zeta_{b}=0.25$ after 30 load cycles. The results indicate that the rate of attenuation in the accumulated rotational is relatively consistent for each simulation at a given intensity of cyclic loading $\left(\zeta_{b}\right)$.

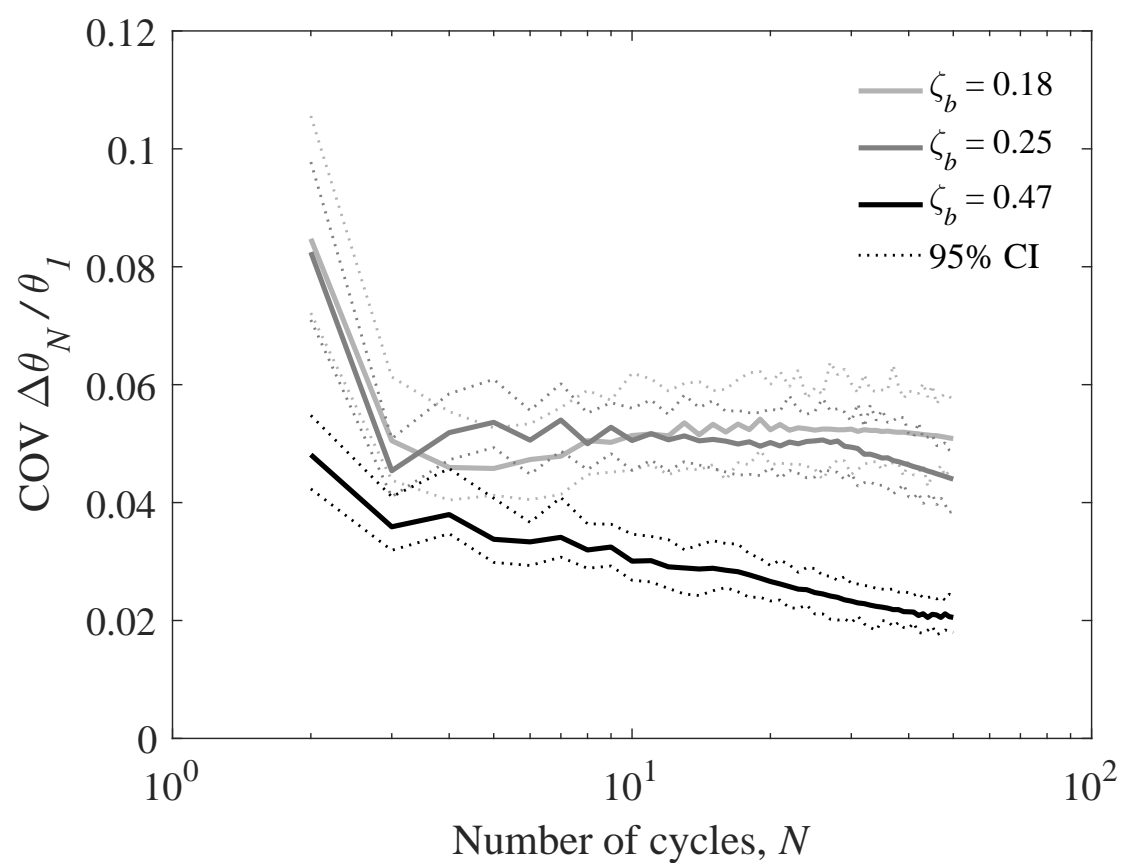

Figure 11: Coefficient of variation (COV) of normalised rotation as a function of number of load cycles. $95 \%$ confidence interval (CI) also shown.

The change in stiffness of the monopile response can be quantified by considering the cyclic secant stiffness, $k_{c}$, which is defined, in a similar manner to Lau (2015), as:

$$
k_{c, i}=\frac{M_{\max , i}-M_{\min , i}}{\theta_{\max , i}-\theta_{\min , i}}
$$

where $M_{\max , i}$ is the maximum bending moment experienced during the $i-t h$ load cycle and $M_{\min , i}$ is the minimum bending moment; $\theta_{\max , i}$ and $\theta_{\min , i}$ refer to the maximum and minimum rotations respectively.

The cyclic secant stiffness is presented in Fig. 12. In the deterministic analysis, the monopile secant stiffness increases with the number of load cycles. Like the accumulated rotation, a rapid increase in secant stiffness initially occurs, followed by an attenuation of the rate of increase with each subsequent load cycle. An increase in foundation stiffness would lead to an increase in the natural frequency of the OWT-foundation system [e.g. 42], which is an important design 
consideration. Cyclic secant stiffness is reduced as the intensity of cyclic loading increases due to more extensive development of plastic strains around the monopile.
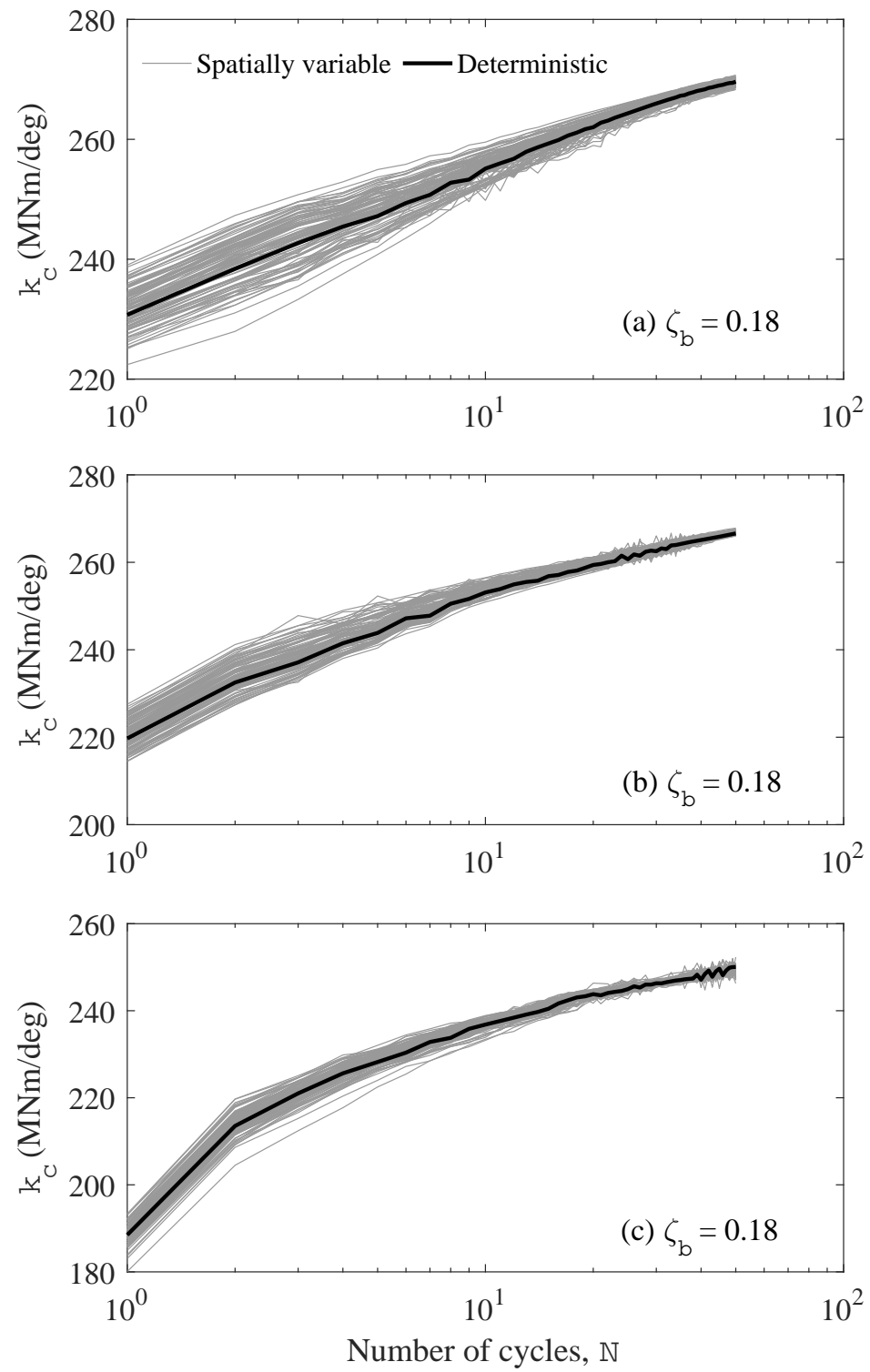

Figure 12: Cyclic secant stiffness, $k_{c}$, in spatially variable clay. (a) $\zeta_{b}=0.18$, (b) $\zeta_{b}=0.25$ and (c) $\zeta_{b}=0.47$.

The stiffening behaviour of the monopile apparently contradicts the degradation of initial stiffness under strain that is exhibited by London Clay but demonstrates the importance of excess pore-water pressures during the undrained cyclic loading of clays. Fig. 13 shows the results of an example deterministic simulation in which the monopile was subjected to 250 load cycles at $\zeta_{b}=0.18$. A zone of reduced pore-water pressure forms on both sides of the monopile due to the generation of negative excess pore-pressures, a result of the overconsolidated state of the clay. The increase in effective stress around the monopile serves to stiffen the response. For 
this case, negative excess pore-water pressures are generated in a zone approximately $5 \mathrm{D}$ wide near the surface, narrowing to $1.5 \mathrm{D}$ at the pile toe.

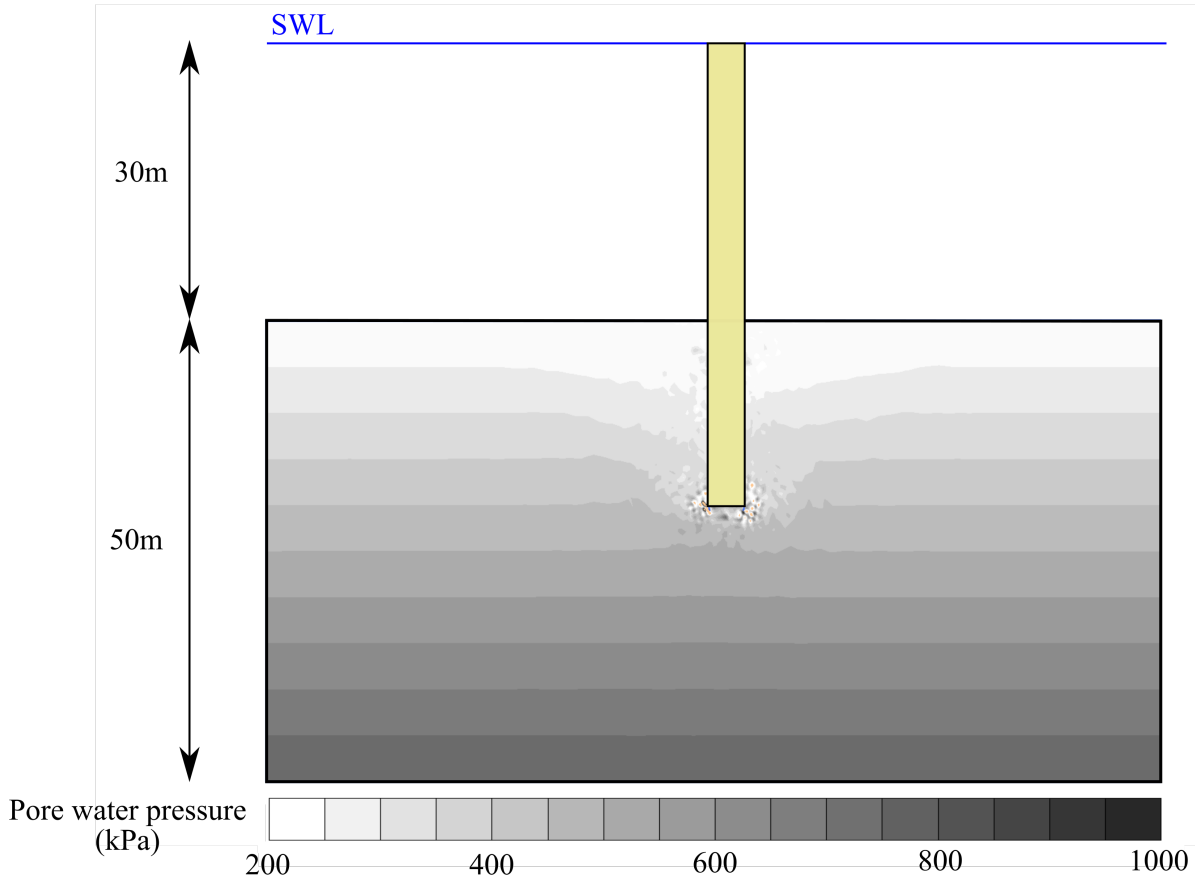

Figure 13: Pore-water pressure around the monopile after 250 load cycles with $\zeta_{b}=0.18$ (deterministic analysis). $\mathrm{SWL}=$ Still Water Level.

Development of negative excess pore-water pressures leading to stiffening behaviour reflects the findings of Lau [34], who observed a similar pattern for one-way loading (i.e. $\zeta_{c} \approx 0$ ) during centrifuge testing in overconsolidated kaolin. Corciulo et al. [11] also found an increase in foundation stiffness (evident through an increase in the natural frequency) in coupled hydro-mechanical FE modelling of a monopile in a dilative sand, which at low permeabilities generated an undrained response and negative excess pore-water pressures under environmental loading.

Much as for accumulated rotation, spatial variability does not affect the general trend of the monopile response, with stiffness increasing at each intensity of cyclic loading. However, there is initially a wide range in secant stiffness. As evident in Fig. 14, the COV of $k_{c}$ reduces with the number of cycles as the stiffness in spatially variable clay converges towards the deterministic value with increasing load cycles. The small increase in COV towards 50 cycles when $\zeta_{b}=0.47$ is likely a result of minor numerical oscillation. The variability of monopile stiffness is higher under a smaller load, which was also the case for accumulated rotation; the practical implication is that there is most uncertainty associated with monopile performance at the fatigue limit state. This emphasises the importance of an adequate characterisation of small-strain stiffness and 
stiffness degradation behaviour during offshore site investigations.

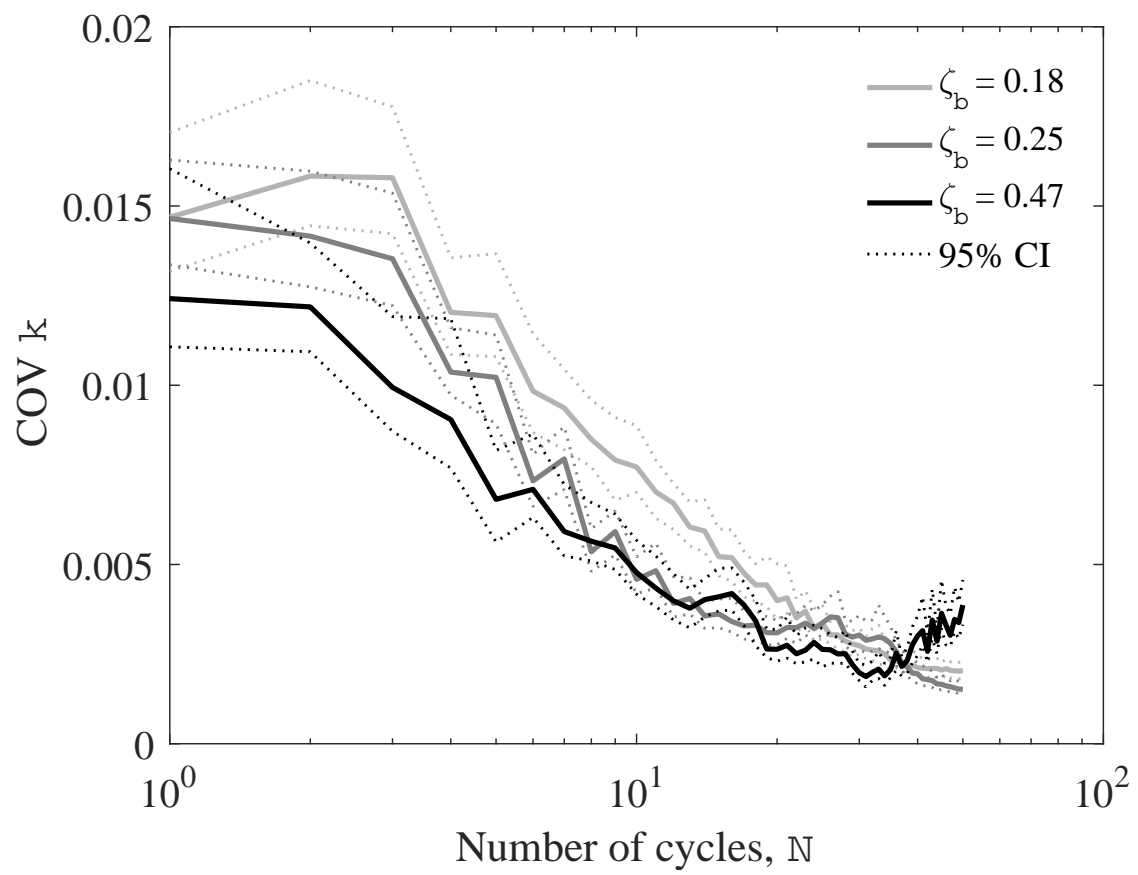

Figure 14: Pore-water pressure around the monopile after 250 load cycles with $\zeta_{b}=0.18$ (deterministic analysis). $\mathrm{SWL}=$ Still Water Level .

\subsection{Dynamic loading}

To assess the performance of the monopile under an extreme dynamic event, the loading record in Fig. 15 was applied. The time history consists of irregular load cycles of different magnitude and frequency and is representative of loading in a storm condition; considering $F_{\max }$ and $F_{\min }$ to be the maximum and minimum forces during the event, $\zeta_{b}$ and $\zeta_{c}$ are equal to 0.44 and -0.68 respectively. Again, 100 Monte Carlo simulations are used to characterise the monopile response in spatially variable clay.

Figure 16 shows the response of the monopile at the mudline. As evident in Fig. 16(a), a permanent rotation accumulates by the end of the time history. Fig. 16(b) illustrates the hysteresis loops that form during the load cycles, with the widest loops corresponding to the largest cycles. Again, the general behaviour in spatially variable clay is similar to that in the deterministic analysis. The greatest variability occurs at the peaks in the applied loading history.

To further investigate the behaviour of the foundation under undrained dynamic loading, the soil response at a series of points around the monopile is inspected. The locations are shown in Fig. 17. The stress-strain response at each point is presented in Fig. 18. Near to the mudline, at a depth of $2 \mathrm{~m}$, there is a clear accumulation of displacement on both sides of the pile as 


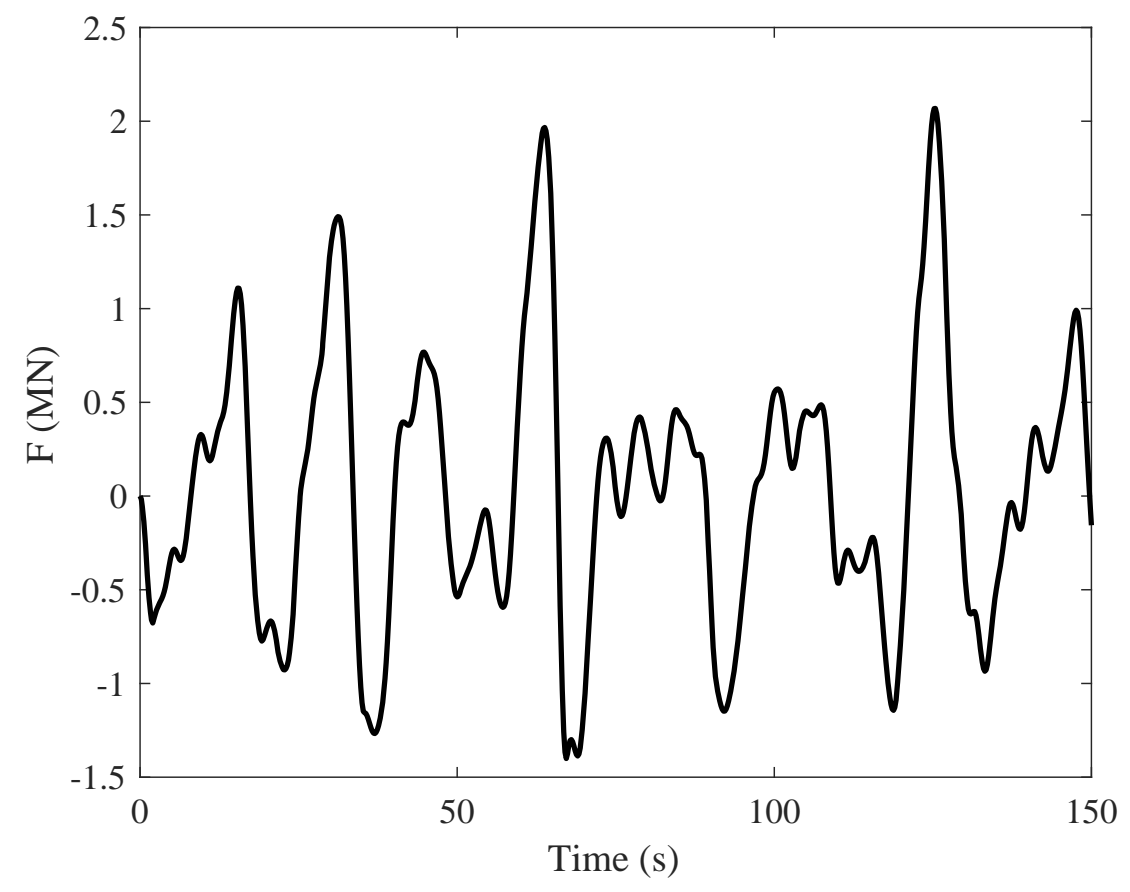

Figure 15: Loading time history.

significant plastic strains develop during each load cycle. The soil recovers only a small amount of strain in each load cycle, indicating the formation of a gap behind the monopile. The peak strength of the clay is mobilised at this depth, leading to widely separated hysteresis loops and strain-softening behaviour with a peak resistance occurring before the maximum shear stress in each load cycle reduces as natural structure is lost. The degradation of clay structure over time at Location 2 is plotted in Fig. 19(a). A rapid decrease in $r$ occurs due to the development of large plastic strains and after 70 s the clay is almost entirely remoulded $(r \approx 1)$. The variability of clay structure is evident in Fig. 19 and results in a large range of peak shear stresses sustained in the soil.

The level of strain experienced midway down the monopile and at the pile toe, shown in Fig. 18(c-d) and (e-f) respectively, is much lower than at the mudline. In Fig. 18(c), the stress-strain response shows hysteresis loops that are centred close to the origin. In contrast, at the pile toe the largest load cycles lead to the accumulation of significant permanent displacements as the induced strain is not entirely recovered upon load reversal. The plastic strains result in a loss of structure, as shown in Fig.19(b), but not severe remoulding as the strain level is not sufficient to mobilise the maximum shear strength of the soil. However, if subjected to more loading cycles over a long period of time the clay structure would continue to degrade as plastic strain accumulates. 

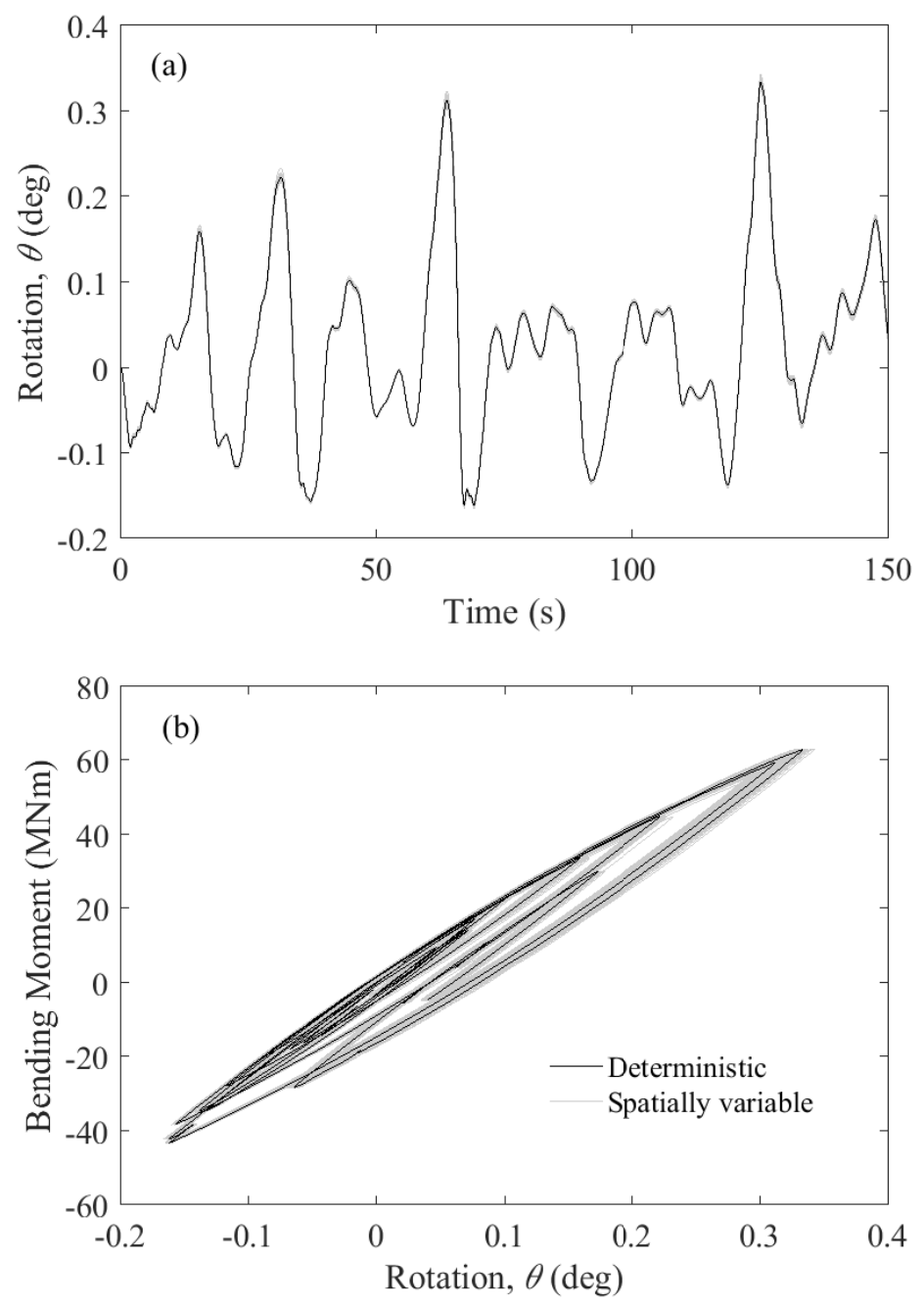

Figure 16: Response of the monopile at the mudline: (a) rotation and (b) moment - rotation relationship.

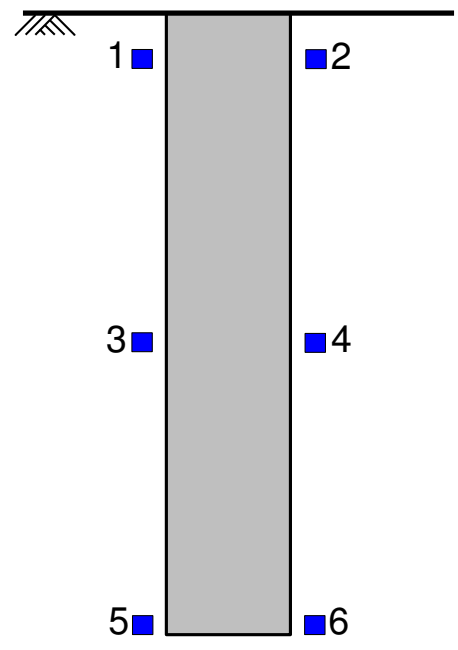

Figure 17: Location of inspection points around monopile. 
- Deterministic Spatially variable
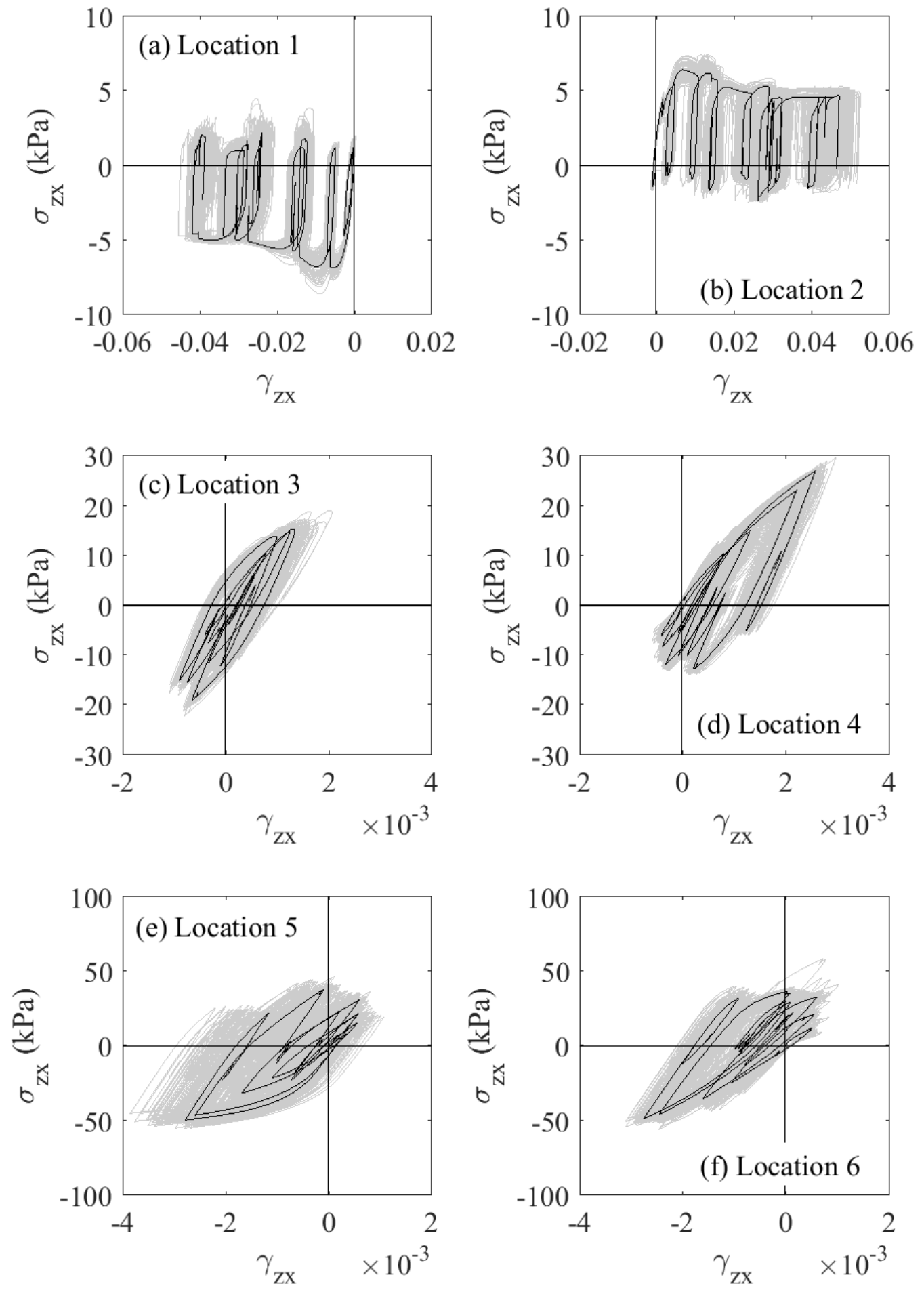

Figure 18: Shear stress - shear strain curves during dynamic loading at locations (a-b) near to the ground surface, (c-d) mid-depth and (d-e) the pile toe. 

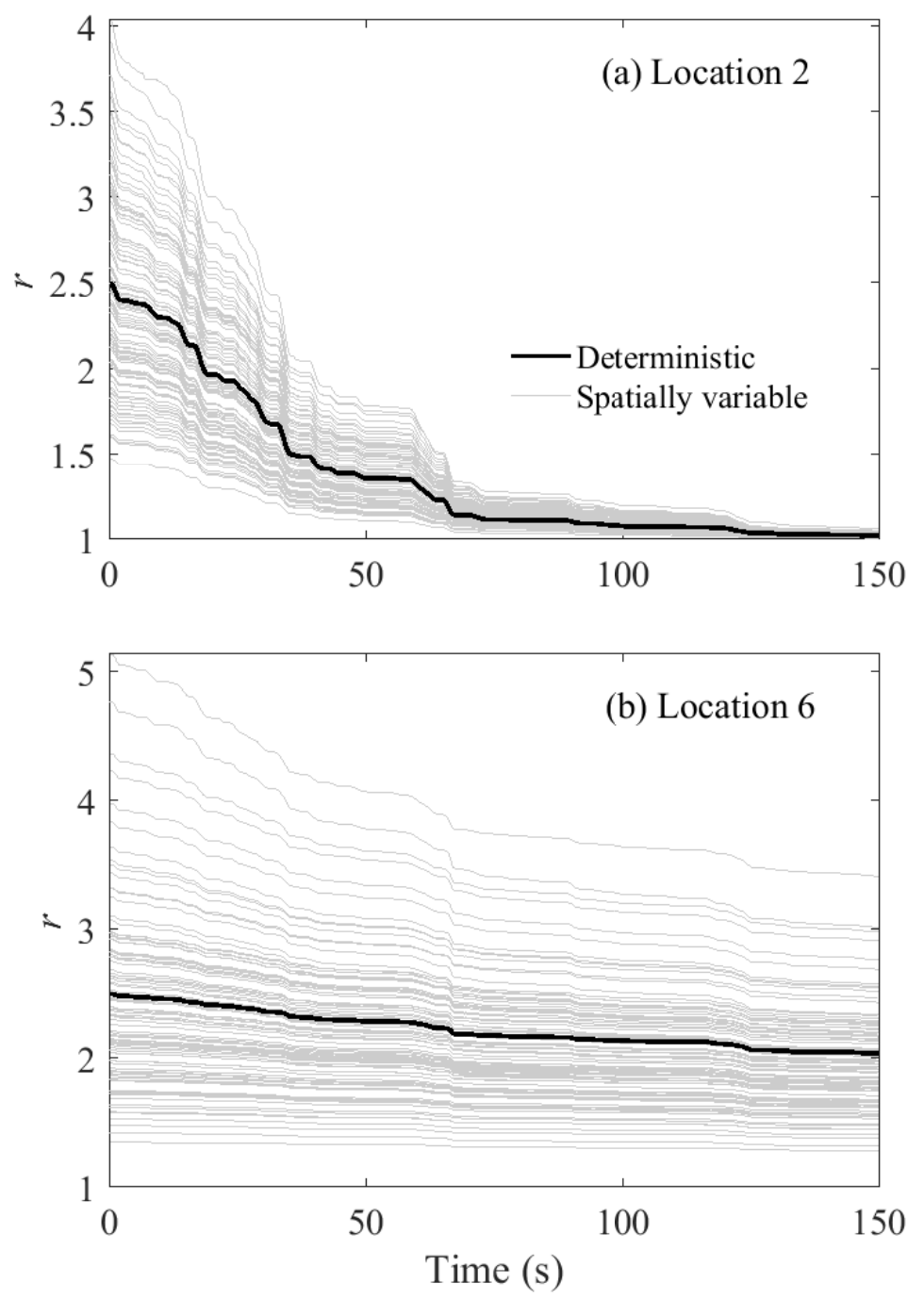

Figure 19: Degradation of clay structure over time (a) near to the mudline and (b) at the pile toe. 
The excess pore-water pressure predicted close to the mudline (Location 2) and at the pile toe (Location 6) is shown in Fig. 20. The development of plastic deformations leads to a general accumulation of negative excess pore-water pressures due to the overconsolidation of the clay, as observed under one-way cyclic loading. At both locations, positive excess porewater pressures are generated in large load cycles when the loading direction is such that the soil is under compression. It is notable that variability in the excess pore-water pressure response increases over time despite the degradation of clay structure and initial stiffness with strain accumulation.
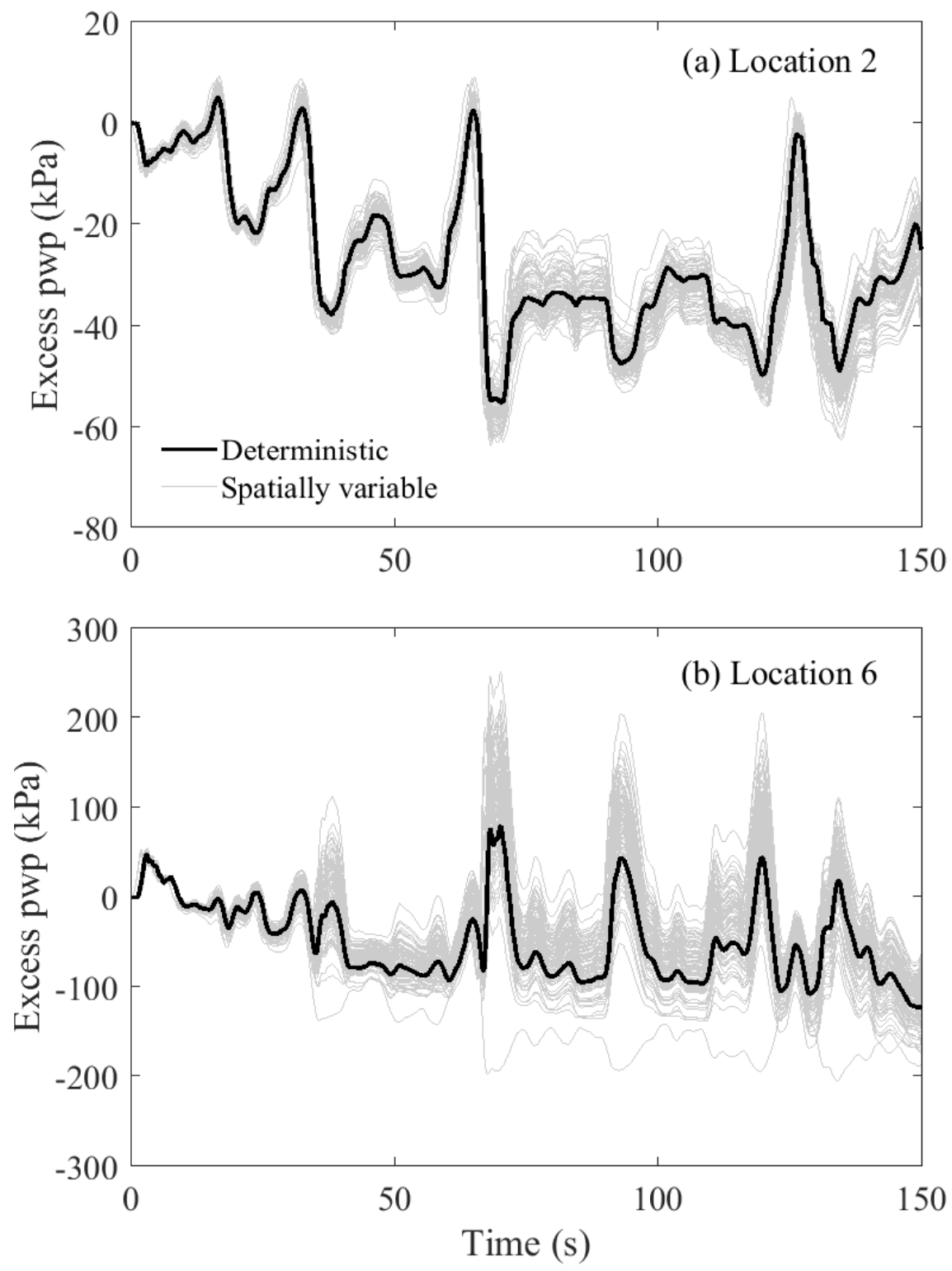

Figure 20: Generation of excess pore-water pressure (pwp) over time (a) near to the mudline and (b) at the pile toe.

The analysis reveals that spatial variability is more influential at the level of a soil element 
compared to its effect on the overall structural response (e.g. Fig. 16). A significant range of soil behaviour in terms of stress-strain response and development of excess pore-water pressures was observed at locations next to the soil-monopile interface at several depths. It can be concluded that monopile performance under lateral cyclic loading is governed by a spatial average of soil properties across the zone of influence. This confirms the advice given in DNVOS-J101 [14, p.168]: A limit state may involve a large volume of soil and it is then governed by the spatial average of the soil property within that volume. The zone extends progressively into the soil mass with an increasing number of load cycles and its size is proportional to the size of the load. This is likely to contribute to the corresponding reductions in the variability of accumulated rotation and cyclic secant stiffness as longer shear planes have been observed to have a greater spatial averaging effect for other foundations in spatially variable clay [e.g. $40,9]$.

\section{Conclusions}

A study of monopile performance under lateral cyclic loading in spatially variable London Clay has been undertaken using 3D FE analysis. The soil was simulated using a multi-surface, kinematic hardening constitutive model able to capture various complex aspects of clay behaviour under undrained cyclic loading including the degradation of shear stiffness, generation of excess pore-water pressures, and remoulding. In the field, soil conditions are heterogeneous and the spatial variability of London Clay was considered in the numerical analysis by coupling the FE model with random field representations of initial stiffness and clay structure (through the RMW parameters $A_{g}$ and $r_{0}$ respectively). The statistical characterisation of the random fields was undertaken considering parameter ranges observed in laboratory tests and Monte Carlo simulation was used to investigate the response of the monopile in spatially variable clay.

The main conclusions are as follows:

- Under one-way cyclic loading, the monopile exhibited ratcheting behaviour where pile rotation accumulates with increasing numbers of load cycles. The rate of rotation accumulation reduced with each load cycle.

- The rotation that occurs in each cycle can vary due to the changing spatial distribution of small-strain stiffness and clay structure around the monopile. However, the results indicate that the rate of increase in permanent accumulated rotation is relatively consistent at a given intensity of cyclic loading. 
- The monopile response stiffened under one-way cyclic loading, which can be attributed to the generation of negative excess pore water pressures around the monopile due to the overconsolidated state of the clay.

- The hysteresis loops tightened with the number of cycles, indicating a reduction in foundation damping.

- Under an extreme dynamic event, variability in the stress-strain response and excess porewater pressure at a series of points around the monopile increased over time as plastic strain accumulated. The variability of the overall structural response was much less than at the soil element level, showing that the behaviour of the monopile is determined by a spatial average of the mobilised clay.

The findings of this study are specific to the soil type, monopile dimensions and loading regimes that were modelled. Further research is needed to investigate the effect of factors such as overconsolidation ratio on the monopile response and gap development at the pile-soil interface. To assess cyclic behaviour in the long term, for example over a 20-year design life, periods of reconsolidation may occur that would alter the strength and stiffness of the soil. A critical state-based constitutive model, such as implemented in this study, would be well-suited to capturing these effects.

Acknowledgements The authors would like to thank the Engineering and Physical Sciences Research Council (EPSRC) and Atkins for funding this research.

[1] Abadie CN, Byrne BW, Houlsby GT. Rigid pile response to cyclic lateral loading: laboratory tests. Géotechnique, 2019; 69(10): 863-876.

[2] Abadie CN, Houlsby GT, Byrne BW. A method for calibration of the Hyperplastic Accelerated Ratcheting Model (HARM). Comput Geotech, 2019;112: 370-385.

[3] Achmus M, Kuo Y-S, Abdel-Rahman, K. Behavior of monopile foundations under cyclic lateral load. Comput Geotech 2009;36(5):725-735.

[4] Barari A, Bagheri M, Rouainia M, Ibsen LB. Deformation mechanisms for offshore monopile foundations accounting for cyclic mobility effects. Soil Dyn Earthq Eng, 2017; 97:439-453.

[5] Cabangon LT, Elia G. and Rouainia M. Modelling the transverse behaviour of circular tunnels in structured clayey soils during earthquakes. Acta Geotech 2019; 14(1):163-178. 
[6] Cafaro F, Cotecchia F. Structure degradation and changes in the mechanical behaviour of a stiff clay due to weathering. Géotechnique 2001;51(5): 441-453.

[7] Charlton TS, Rouainia M, Gens A. Numerical analysis of suction embedded plate anchors in structured clay. Appl Ocean Res 2016; 61: 156-166.

[8] Charlton TS, Rouainia M. Probabilistic analysis of the uplift resistance of buried pipelines in clay. Ocean Eng 2019;186: 105891.

[9] Charlton TS, Rouainia M. Uncertainty quantification of offshore anchoring systems in spatially variable soil using sparse polynomial chaos expansions. Int J Numer Meth Eng 2019;120(6): 748-767.

[10] Chen C, Duffour P. Modelling damping sources in monopile-supported offshore wind turbines. Wind Energy, 201821;11: 1121-1140.

[11] Corciulo S, Zanoli O, Pisanò F. Transient response of offshore wind turbines on monopiles in sand: role of cyclic hydro-mechanical soil behaviour. Comput Geotech 2017; 83: 221238.

[12] Cuellar P. Pile foundations for offshore wind turbines: numerical and experimental investigations on the behaviour under short-term and long-term cyclic loading. $\mathrm{PhD}$ thesis, Technical University of Berlin; 2011.

[13] Depina I, Le TMH, Eiksund G, Benz T. Behavior of cyclically loaded monopile foundations for offshore wind turbines in heterogeneous sands. Comput Geotech 2015; 65: 266-277.

[14] DNV. DNV-OS-J101 Design of offshore wind turbine structures. Oslo, Norway: Det Norske Veritas AS; 2014.

[15] DNV GL. DNVGL-ST-0126 Support structures for wind turbines. Edition July 2018.

[16] El Haj A-K, Soubra AH, Fajoui J. Probabilistic analysis of an offshore monopile foundation taking into account the soil spatial variability. Comput Geotech 2019; 106: 205-216.

[17] Elia G, Rouainia M. Seismic Performance of Earth Embankment Using Simple and Advanced Numerical Approaches. J Geotech Geoenviron Eng 2013; 139(7): 1115-1129. 
[18] Elia G, Rouainia M. Performance evaluation of a shallow foundation built on structured clays under seismic loading. B Earthq Eng 2014; 12(4): 1537-1561.

[19] Elia G, and Rouainia, M. Investigating the cyclic behaviour of clays using a kinematic hardening soil model. Soil Dyn Earthq Eng 2016; 88: 399-411.

[20] Gasparre A. Advanced laboratory characterisation of London Clay. PhD thesis. Imperial College; 2005.

[21] Gasparre A, Coop MR. Quantification of the effects of structure on the compression of a stiff clay. Can Geotechn J 2008;45(9): 1324-1334.

[22] Gasparre A, Nishimura S, Coop MR, Jardine RJ. The influence of structure on the behaviour of London Clay. Géotechnique 2007; 57(1): 19-31.

[23] Gonzàlez NA, Rouainia M, Arroyo M, Gens A. Analysis of tunnel excavation in London Clay incorporating soil structure. Géotechnique 2012; 62(12): 1095-1109.

[24] Grammatikopoulou A, Zdravkovic L, Potts DM. The influence of previous stress history and stress path direction on the surface settlement trough induced by tunnelling. Géotechnique 2008; 58(4): 269-281.

[25] GWEC. Global Wind Report. Global Wind Energy Council, Brussels, Belgium; 2020.

[26] Haldar S, Sivakumar Babu GL. Effect of soil variability on the response of laterally loaded pile in undrained clay. Comput and Geotech 2008; 35(4):537-547

[27] Hight DW, GasparreA, Nishimura S, Minh NA, Jardine RJ, Coop MR. Characteristics of the London Clay from the Terminal 5 site at Heathrow Airport. Géotechnique 2007; 57(1): 3-18.

[28] Hight DW, McMillan F, Powell JJM, Jardine RJ, Allenou CP. Some characteristics of London Clay. In Characterisation and Engineering Properties of Natural Soils. Balkema, Lisse, the Netherlands. 2:851-907; 2003.

[29] Houlsby GT, Abadie CN, Beuckelaers WJAP, Byrne BW. A model for nonlinear hysteretic and ratcheting behaviour. Int J Solids Struct, 2017;120: 67-80.

[30] Keaveny JM, Nadim F, Lacasse S. Autocorrelation functions for offshore geotechnical data. 5th ICOSSAR. San Francisco, USA; 1989. 
[31] Klinkvort RT, Hededal O. Lateral response of monopile supporting an offshore wind turbine. P I Civil Eng-Geotech, 2013;166(2): 147-158.

[32] Lacasse S, Nadim F. Uncertainties in characterising soil properties. Uncertainty in the geologic environment: from theory to practice. New York: ASCE: 49-75, 1996.

[33] Lai Y, Wang L, Hong Y, He B. Centrifuge modeling of the cyclic lateral behavior of largediameter monopiles in soft clay: Effects of episodic cycling and reconsolidation. Ocean Eng, 2020;200: 107048.

[34] Lau BH. Cyclic behaviour of monopile foundations for offshore wind turbines in clay. $\mathrm{PhD}$ thesis, University of Cambridge; 2015.

[35] Le TMH, Eiksund GR, Strøm PJ, Saue M. Geological and geotechnical characterisation for offshore wind turbine foundations: A case study of the Sheringham Shoal wind farm. Eng Geol 2014; 177: 40-53.

[36] LeBlanc C. Design of offshore wind turbine support structures: Selected topics in the field of geotechnical engineering. Aalborg University; 2009.

[37] LeBlanc C, Byrne BW, Houlsby GT. Response of stiff piles to random two-way lateral loading. Géotechnique, 2010;60(9): 715-721.

[38] LeBlanc C, Houlsby GT, Byrne BW. Response of stiff piles in sand to long-term cyclic lateral loading. Géotechnique 2010; 60(2): 79-90.

[39] Li C, Der Kiureghian A. Optimal Discretization of Random Fields. Journal of Engineering Mechanics 1993; 119(6): 1136-1154.

[40] Li J, Tian Y, Cassidy M. Failure Mechanism and Bearing Capacity of Footings Buried at Various Depths in Spatially Random Soil. J Geotech Geoenviron Eng 2015;141(2): 04014099

[41] Li Z, Haigh SK, Bolton MD. Centrifuge modelling of mono-pile under cyclic lateral loads. 7th Int Conf Phys Model Geo, Zurich, 2010; 965-970.

[42] Lombardi D, Bhattacharya S, Muir Wood D. Dynamic soilâĂŞstructure interaction of monopile supported wind turbines in cohesive soil. Soil Dyn Earthq Eng 2013; 49: 165180. 
[43] Panayides S, Rouainia M, Muir Wood D. Influence of degradation of structure on the behaviour of a full-scale embankment. Can Geotech J 2012; 49(3): 344-356.

[44] Phoon KK, Kulhawy FH. Characterization of geotechnical variability. Can Geotech J 1999;36(4): 612-624.

[45] Plaxis. PLAXIS 3D AE - Reference manual. Delft: Plaxis bv; 2016.

[46] Plaxis. PLAXIS MoDeTo - Manual. Delft: Plaxis bv; 2018.

[47] Rouainia M, Muir wood D. A kinematic hardening constitutive model for natural clays with loss of structure. Géotechnique 2000; 50(2):153-164.

[48] Rouainia M, Muir Wood D. Computational aspects in finite strain plasticity analysis of geotechnical materials. Mech Res Commun, 2006;33(2): 123-133.

[49] Sudret B, Der Kiureghian A. Stochastic finite elements and reliability: a state-of-the-art report. Berkeley: University of California; 2000.

[50] Trhlíková J, Mašín D, Boháč J. Small-strain behaviour of cemented soils. Géotechnique 2012; 62(10): 943-947.

[51] Viggiani GMB, Atkinson JH. Stiffness of fine-grained soil at very small strains. Géotechnique $1995 ; 45(2):$ 249-265.

[52] Vořechovský M. Simulation of simply cross correlated random fields by series expansion methods. Struct Saf 2008; 30(4): 337-363.

[53] WindEurope. Offshore wind in Europe - Key trends and statistics 2019. Brussels, Belgium; 2020.

[54] Yimsiri S. Pre-failure deformation characteristic of soils: Anisotropy and soil fabric. PhD thesis. University of Cambridge; 2001.

[55] Zhang C, White D, Randolph M. Centrifuge Modeling of the Cyclic Lateral Response of a Rigid Pile in Soft Clay. J Geotech Geoenviron Eng 2011; 137(7): 717-729.

[56] Zhao J, Sheng D, Rouainia M, Sloan SW. Explicit stress integration of complex soil models. Int J Numer Anal Meth, 2005; 29(12):1209-1229. 
520

522

\section{List of Tables}

1 Calibrated RMW parameters for London Clay. Shading indicates random parameters in the current study. . . . . . . . . . . . . . . 6 


\section{List of Figures}

1 Monopile foundation for an offshore wind turbine. SWL $=$ Still Water Level. . 4

2 RMW model predictions and laboratory data for undrained triaxial compression tests on London Clay: (a) stress path; (b) stress-strain response. Laboratory data from Gasparre [20]; $26.5=26.5 \mathrm{~m}$ sample depth, $\mathrm{i}=$ isotropic consolidation, UC $=$ undrained compression test. . . . . . . . . . . . . . 7

3 Profile of $r_{0}$ with depth showing laboratory data from Heathrow T5 site (replotted from [23]); data from references therein) and random field realisation. . . . 8

4 Stiffness degradation of London Clay in undrained triaxial compression tests. Numerical simulations undertaken with $r_{0}=2.5$ unless otherwise stated. . . . 9

5 Finite element mesh. . . . . . . . . . . . . . . . 11

6 Computational framework for Monte Carlo simulation. . . . . . . . . . . . . . 13

7 Random field realisations of (a) $r_{0}$ and (b) $A_{g} \ldots \ldots \ldots$

8 Lateral displacement of the monopile after 50 load cycles, with 100 simulations in spatially variable clay and the deterministic case. (a) $\zeta_{b}=0.18$, (b) $\zeta_{b}=0.25$, and $(\mathrm{c}) \zeta_{b}=0.47 \ldots \ldots \ldots \ldots \ldots \ldots$

9 Bending moment - rotation of the monopile at the mudline in spatially variable clay (100 simulations) after 50 load cycles with (a) $\zeta_{b}=0.18$, (b) $\zeta_{b}=0.25$, and

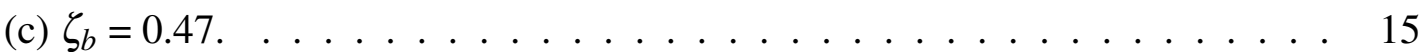

10 Normalised accumulated rotation at the mudline in spatially variable clay. . . . 16

11 Coefficient of variation (COV) of normalised rotation as a function of number of load cycles. $95 \%$ confidence interval (CI) also shown. . . . . . . . . . . . . 17

12 Cyclic secant stiffness, $k_{c}$, in spatially variable clay. (a) $\zeta_{b}=0.18$, (b) $\zeta_{b}=0.25$ and (c) $\zeta_{b}=0.47 \ldots \ldots \ldots \ldots \ldots$

13 Pore-water pressure around the monopile after 250 load cycles with $\zeta_{b}=0.18$ (deterministic analysis). SWL $=$ Still Water Level. . . . . . . . . . . . . . .

14 Pore-water pressure around the monopile after 250 load cycles with $\zeta_{b}=0.18$ (deterministic analysis). SWL $=$ Still Water Level. . . . . . . . . . . . . . . 20

15 Loading time history. . . . . . . . . . . . . . . . . . . . . 21 
16 Response of the monopile at the mudline: (a) rotation and (b) moment - rotation

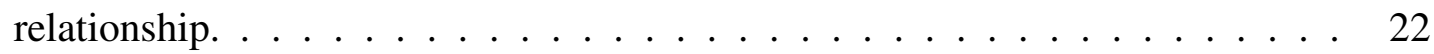

17 Location of inspection points around monopile. . . . . . . . . . . . . . 22

18 Shear stress - shear strain curves during dynamic loading at locations (a-b) near to the ground surface, $(\mathrm{c}-\mathrm{d})$ mid-depth and $(\mathrm{d}-\mathrm{e})$ the pile toe. . . . . . . . . . 23

19 Degradation of clay structure over time (a) near to the mudline and (b) at the pile toe. . . . . . . . . . . . . . . . . . . 24

20 Generation of excess pore-water pressure (pwp) over time (a) near to the mudline and (b) at the pile toe. . . . . . . . . . . . . . . 25 